Florida International University FIU Digital Commons

3-28-2014

\title{
Acoustic Investigation of Production of Clusters by Saudi Second Language Learners of English
}

Hussain Almalki

Florida International University, halma009@fiu.edu

DOI: $10.25148 /$ etd.FI14040872

Follow this and additional works at: https://digitalcommons.fiu.edu/etd

Part of the First and Second Language Acquisition Commons, and the Phonetics and Phonology Commons

\section{Recommended Citation}

Almalki, Hussain, "Acoustic Investigation of Production of Clusters by Saudi Second Language Learners of English" (2014). FIU Electronic Theses and Dissertations. 1235.

https://digitalcommons.fiu.edu/etd/1235 


\title{
FLORIDA INTERNATIONAL UNIVERSITY
}

Miami, Florida

\section{ACOUSTIC INVESTIGATION OF PRODUCTION OF CLUSTERS BY SAUDI SECOND LANGUAGE LEARNERS OF ENGLISH}

\author{
A thesis submitted in partial fulfillment of \\ the requirements for the degree of \\ MASTER OF ARTS \\ in \\ LINGUISTICS \\ by
}

Hussain Almalki 
To: Dean Kenneth G. Furton

College of Arts and Sciences

This thesis, written by Hussain Almalki, and entitled Acoustic Investigation of Production of Clusters by Saudi Second Language Learners of English, having been approved in respect to style and intellectual content, is referred to you for judgment.

We have read this thesis and recommend that it be approved.

Virginia C. Mueller Gathercole

Tometro Hopkins

Mehmet Yavaş, Major Professor

Date of Defense: March 28, 2014

The thesis of Hussain Almalki is approved.

Dean Kenneth G. Furton

College of Arts and Sciences

Dean Lakshmi N. Reddi

University Graduate School

Florida International University, 2014 
(C) Copyright 2014 by Hussain Almalki

All rights reserved. 


\section{DEDICATION}

To the one and only, my lovely wife, Sahar! 


\section{ACKNOWLEDGMENTS}

I would like to express my sincere gratitude to my advisor Dr. Mehmet Yavaş for the continuous support of my research, for his patience, motivation, enthusiasm, and immense knowledge. His guidance helped me in all the time of research and writing of this thesis. I could not have imagined having a better advisor and mentor for my MA study.

I would also like to thank the rest of my thesis committee: Dr. Virginia C. Mueller Gathercole and, Dr. Tometro Hopkins, for their encouragement, insightful comments, and commitment of time to this project.

Special thanks and much love go to my lovely wife, Sahar, for her kindness and endless support not only throughout this project but always.

Many thanks and appreciation goes to my friend, Emily Byers, for her suggestions and help in editing this work.

I, finally, would like to thank Dr. Jianbin Zhu for his assistance in processing the results of this study. 


\title{
ABSTRACT OF THE THESIS \\ ACOUSTIC INVESTIGATION OF PRODUCTION OF CLUSTERS BY SAUDI SECOND LANGUAGE LEARNERS OF ENGLISH
}

\author{
by \\ Hussain Almalki \\ Florida International University, 2014 \\ Miami, Florida \\ Professor Mehmet Yavaş, Major Professor
}

Production errors made by second language (L2) learners of English have been attributed to markedness, L1 transfer or input frequency (cf. Major, 2001; Edwards \& Zampini, 2008; Baptista, Rauber, \& Watkins, 2009). This thesis examines the production of 17 English initial consonant clusters (e.g., /pr/ in pray) in a markedness relationship, whereby clusters with greater sonority distance between the first and second consonants are unmarked and clusters with smaller sonority distance between the first and second consonants are marked, by two groups of Saudi Arabian L2 English learners. It also explores the effect of input frequency and L1 transfer. Participants were asked to read 60 sentences and their reading was recorded for acoustic analysis. Analysis showed that prothesis was always used to simplify the clusters, and that, the duration of the prothetic vowel tended to get longer when clusters become more marked. Intermediate participants had greater degree of difficulty in producing the clusters and tended to insert a longer prothetic vowel in general. Markedness explained the performance on \#sC clusters; however, performance on non \#sC clusters was best explained by L1 transfer. Results further indicated that input frequency was irrelevant to this study. 


\section{TABLE OF CONTENTS}

CHAPTER

PAGE

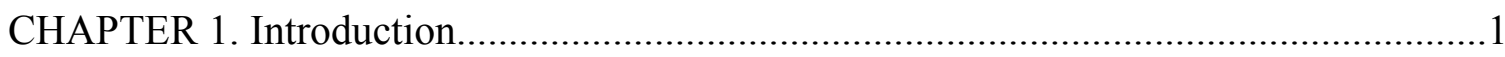

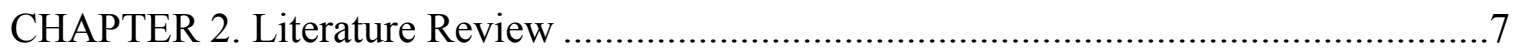

2.1. Interlanguage Phonology ........................................................................ 7

2.1.1. Transfer and the Contrastive Analysis Hypothesis .......................... 9

2.1.2. Markedness in Interlanguage Phonology ......................................12

2.1.2.1. Markedness Differential Hypothesis................................12

2.1.2.2. Structural Conformity Hypothesis ..................................14

2.2. The Ontogeny Phylogeny Model .................................................................. 16

2.2.1. Chronological Corollary of The OPM ..........................................16

2.2.2. Stylistic Corollary of The OPM ..................................................17

2.2.3. Similarity Corollary of The OPM ..................................................18

2.2.4. Markedness Corollary of The OPM...............................................18

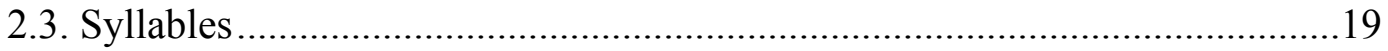

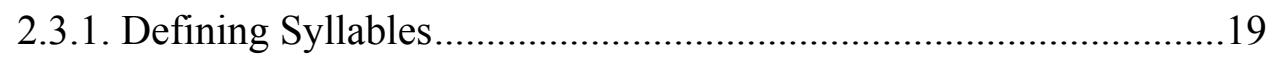

2.3.2. Sonority Sequencing Principle..................................................22

2.4. Role of Input Frequency on Cluster Acquisition ........................................29

2.5. Studies on Onset Clusters By Arabic L2 Learners of English........................31

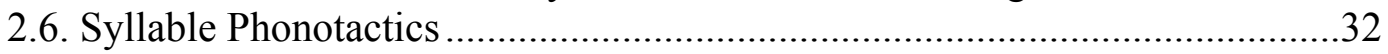

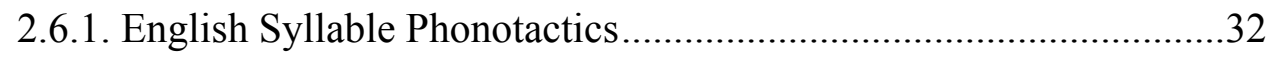

2.6.2. Arabic Syllable Phonotactics .....................................................33

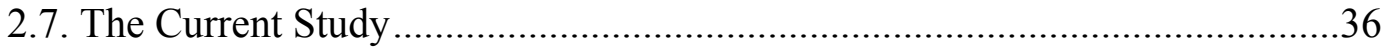

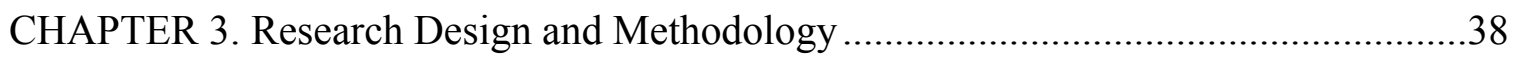

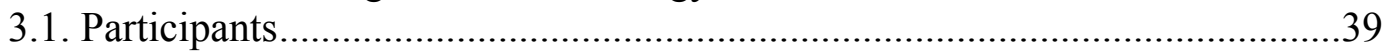

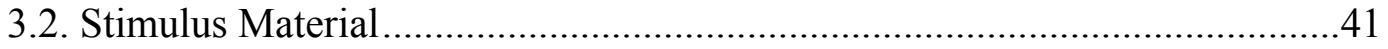

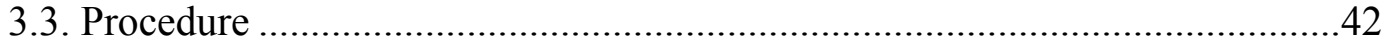

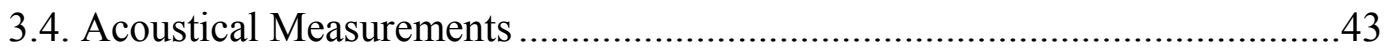

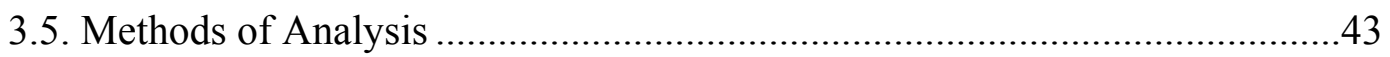

3.5.1. Markedness Based Analysis ....................................................44

3.5.2. Frequency Based Analysis ...........................................................45

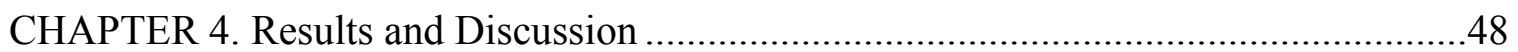

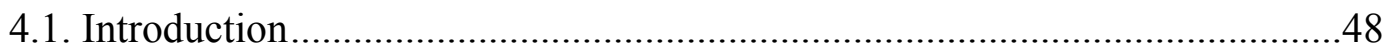

4.2. Results Based on Markedness by Sonority ..............................................50

4.2.1. Results From \#sC Clusters Groups .............................................50

4.2.2. Results From Non \#sC Clusters Groups ......................................58

4.3. Results From Frequency Based Analysis ................................................66

4.4. Vowel Duration.......................................................................................67

4.4.1. Vowel Duration For \#sC Clusters Groups .....................................68

4.4.2. Vowel Duration For Non \#sC Clusters Groups .............................70 
4.5. Summary of The Results.

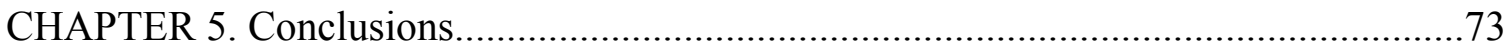

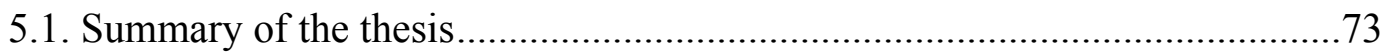

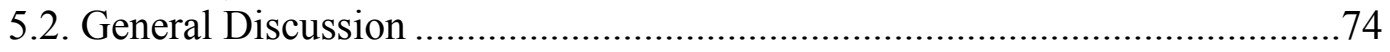

5.2.1 Input Frequency in SLA......................................................... 74

5.2.2 The Ontogeny Phylogeny Model .............................................. 74

5.2.2.1. Markedness .................................................................. 74

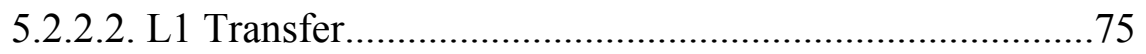

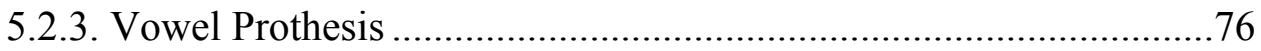

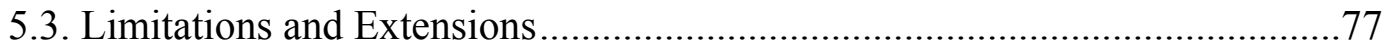

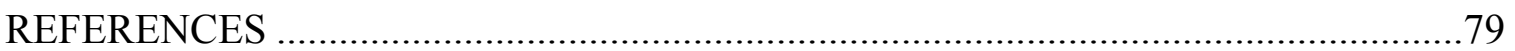

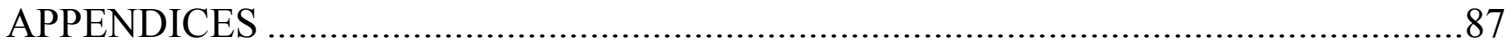




\section{LIST OF TABLES}

TABLE

PAGE

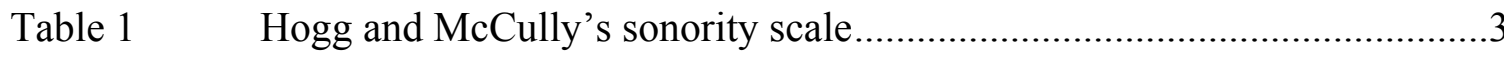

Table 2 Representation of simple syllable structure ........................................20

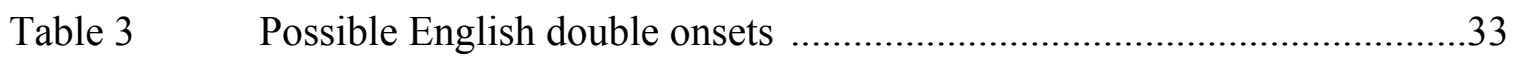

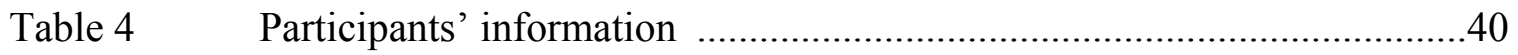

Table 5a Non \#sC clusters based on Sonority Distance ......................................44

Table 5b \#sC clusters based on Sonority Distance ..............................................45

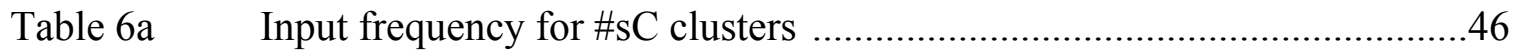

Table $6 \mathrm{~b} \quad$ Input frequency for non \#sC clusters .............................................47

Table 7 Independent Samples t-test for percentages of correct production

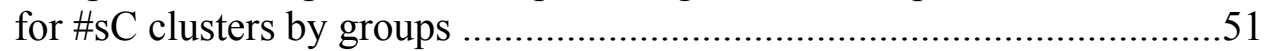

Table $8 \quad$ Paired samples t-test results for percentages of correct production for $\#_{\mathrm{s} C}$ clusters sonority distances by intermediate group ......................56

Table 9 OPM predicted pattern for $\mathrm{A}_{\mathrm{s}} \mathrm{C}$ clusters and groups performance ............58

Table 10 Independent Samples t-test for percentages of correct production for non $\#_{\mathrm{sC}}$ clusters by groups

Table 11 Paired samples t-test results for percentages of correct production for Non \#sC clusters sonority distances by advanced group

Table 12 Paired samples t-test results for percentages of correct production for Non $\mathrm{ASC}$ clusters sonority distances by intermediate group

Table 13 OPM predicted pattern for non $\#_{\mathrm{s}} \mathrm{C}$ clusters and groups performance .....65

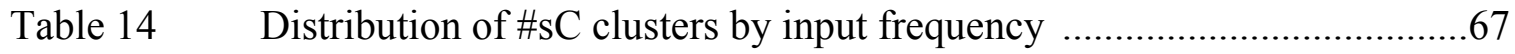

Table 15 Distribution of non \#sC clusters by input frequency ............................67 


\section{LIST OF FIGURES}

FIGURE

PAGE

Figure 1.1.a Components of the Interlanguage System ........................................

Figure 2.1.a The Ontogeny Phylogeny Model. Normal Phenomena ..........................17

Figure 2.1.b The Ontogeny Phylogeny Model. Similar Phenomena ...........................18

Figure 2.1.c The Ontogeny Phylogeny Model. Marked Phenomena ..........................19

Figure 3.1.a Hierarchal Representation of the Syllable Structure ..............................21

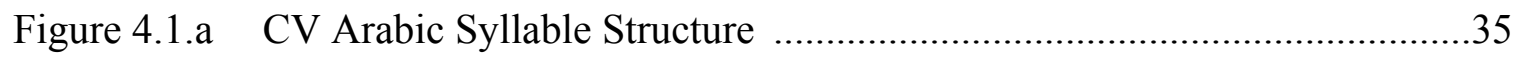

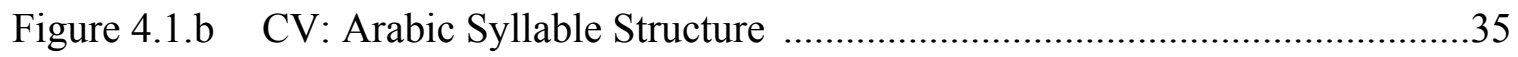

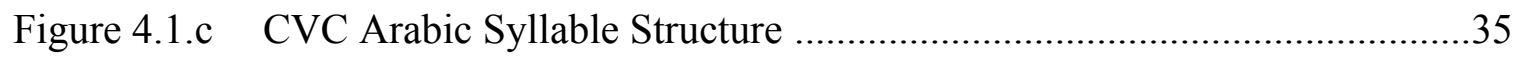

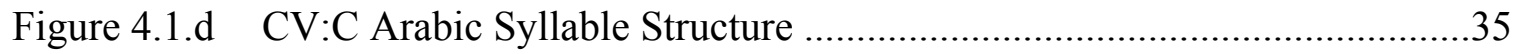

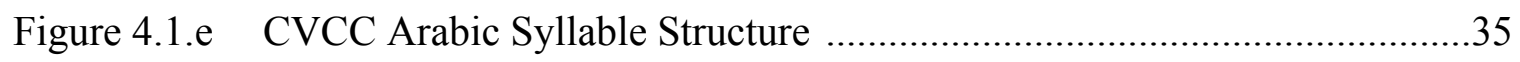

Figure 5.1.a The Representations of \#sC Clusters - Branching Onset ........................50

Figure 5.1.b The Representations of $\#_{\mathrm{s} C}$ Clusters - Complex Onset ...........................50

Figure 5.1.c The Representations of \#sC Clusters - Adjunct Onset ...........................50

Figure 5.1.d The Representations of \#sC Clusters - Extrasyllabic Onset .....................50

Figure 6.1.a The Percentages of Correct Production for \#sC Clusters ........................53

Figure 6.1.b Box plot for the percentages of correct production for \#sC

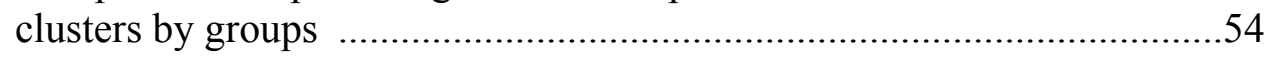

Figure 6.2.a The Percentages of Correct Production for Non \#sC Clusters ................60

Figure 6.2.b Box plot for the percentages of correct production for non $\mathrm{AsC}_{\mathrm{s}}$ clusters by groups 
Figure 7.1.a The Duration of The Prothetic Vowel for \#sC Cluster Groups ...............69

Figure 7.1.b The Duration of The Prothetic Vowel for Non \#sC Cluster Groups ........71 


\section{CHAPTER 1. Introduction}

Within the realm of second language (L2) phonology, the acquisition of consonant clusters seems to pose great difficulty for speakers with first languages (L1) that do not allow consonant clusters. It is typically thought that the non-native productions by adult L2 speakers are due to differences between the L1 and the L2 linguistic systems. L1 transfer, whereby phonological rules or items from the L1 are transferred to the L2, has been highly used in the literature to account for many of the non-native productions (Lado, 1957; Selinker, 1972; Odlin, 1989). This explanation, for instance, was widely used to account for errors made by Arabic L2 learners of English. According to Broselow (1992), production errors in the L2 can be attributed either to transfer of L1 phonological rules or to the violation of some universal tendencies. Languages of the world, for instance, are different in their syllable phonotactics: On one hand, some languages are very restricted in their syllable structure by only allowing Consonant (henceforth C) + Vowel (henceforth V) sequencing; on the other hand, other languages are more flexible in allowing more complex structures. In the instances where L1 is restricted and L2 is more flexible, L1 phonotactic constraints would likely to be transferred to the L2. However, markedness has also been discussed in the literature as a plausible explanation for L2 acquisition patterns.

In the discussion of the topic, markedness relationships among clusters are often determined by “implicational patterns" (Greenberg, 1965). According to markedness principles, if a language allows complex consonant clusters in the onset or coda, then, it necessarily will allow simple consonants in the onset or coda. Another example would be, if a language allows [obstruent] + [nasal], then it is also expected to have [obstruent] 
+ [liquid] because according to the Sonority Sequencing Principle these clusters are more common, as will be further discussed. The same goes for the degree of complexity by number; if a language allows three consonants to occupy the onset position or the coda position then it will necessarily allow clusters with two members in the same position (Clements, 1990; Eckman, 2008). According to Eckman (2008) this relation is unidirectional; meaning that if a language allows a singleton consonant in the onset or coda position, then that does not imply the presence of complex clusters in that language and so on. In other words, the more members in the cluster, the more marked the cluster would be (Eckman, 2008). From this, one may conclude that clusters have complex phonological structures in general, and their relative degrees of complexity vary depending on their position and number of members. That is to say, there is an expected hierarchy among clusters according to their relative degrees of markedness, ranging from least marked clusters to most marked clusters. According to Eckman (1977), the relative degree of markedness of a given structure is not limited to L1 acquisition but can also be observed in L2 acquisition. Eckman (1977) proposed that less marked structures are easier to acquire than more marked ones.

One approach that is widely used in determining the markedness among syllables is sonority. Sonority refers to the principles that govern the arrangement of sounds into syllables. Accordingly, sounds that are made with greater "degree of opening in the vocal tract" are more sonorant (Yavaş, 2011). In the acquisition of the L1, sonority seems to play an important role in determining which sound sequence is permissible in the language, with the help of what is known as Sonority Indices (SI) of sounds (cf. Yavaş, 2003). The idea of sonority is well represented in the Sonority Sequencing Principle 
(henceforth SSP). The SSP states that any syllable must contain a segment that constitutes its sonority peak (i.e., nucleus) preceded by a segment or a sequence of segments with increasing values of sonority and/or followed by segment or a sequence of segments with decreasing values of sonority (Selkirk, 1984; Clements, 1990; Yavaş, 2003). Since, interlanguage system is behaving like a natural language, it is expected to adhere to the SSP. For our purposes, sonority is very relevant because it has number of constraints that determine the degree of markedness of clusters. Such constraints are explained by the Sonority Dispersion Principle (Clements, 1990), which states "sonority is maximally dispersed in the initial demisyllable and minimally dispersed in the final demisyllable". Therefore, it is a universal tendency that more natural sequences in initial consonant clusters are in clusters with greater sonority distances between the members of those clusters (Yavaş, 2003). The sonority indices (or values) for individual sounds are represented in the sonority scale below.

Table 1: Hogg and McCully's sonority scale (adapted from Hogg and McCully, 1987)

\begin{tabular}{lc}
\hline Sound & SI (Sonority Index) \\
\hline Low vowels & 10 \\
\hline Mid vowels & 9 \\
\hline High vowels & 8 \\
\hline Flaps & 7 \\
\hline Laterals & 6 \\
\hline Nasals & 5 \\
\hline Vd. Fricatives & 4 \\
\hline Vs. Fricatives & 3 \\
\hline Vd. Stops & 2 \\
\hline Vs. Stops & 1 \\
\hline
\end{tabular}


For example, in a double onset cluster situation, which is the focus of this study, $/ \mathrm{pr} /$ is more natural onset than /fr/ because /p/ (the voiceless stop) in $/ \mathrm{pr} /$ is with sonority index 1 on the sonority scale and the $/ \mathrm{r} /$ sound is with sonority index 7 providing greater sonority distance (Son.D) between the first consonant (C1) and the second consonant (C2) and therefore making a more natural onset. On the other hand, / $\mathrm{fr} /$ is only moving from sonority index 3 for $/ \mathrm{f} /$ to sonority index 7 for $/ \mathrm{r} /$ making a smaller sonority distance between $\mathrm{C} 1$ and $\mathrm{C} 2$ (a discussion of the sonority scale will be introduced in the next chapter). There are, however, some sequences that violate the SSP because they give "negative sonority" such as /st, sk, sp/ in the onset position, which makes them even more marked. These clusters violate the SSP, here, because the sonority sequencing from the word boundary toward the peak is going from higher sonority to lower sonority before the peak (Barlow, 2001; Yavaş, 2003, 2010). Such violation (i.e., SSP-violation) makes these clusters the most marked clusters in the onset position.

Although transfer and universal tendencies seem to explain most of the acquisition behaviors and error patterns found in interlanguage phonology (cf. Eckman, 2008), a growing body of literature on the production of consonant clusters discussed the possible impact of the frequency of the input. Input frequency has been reported to provide a better explanation for some error patterns found in child language (e.g., Zamuner, Gerken, \& Hammond, 2005). Zamuner et al. (2005) suggested that children would acquire more frequent but "marked" forms before they would acquire the "infrequent" but unmarked ones.

In the field of second language acquisition (SLA), the role of input frequency is considered relatively new with only few studies in the literature that have looked at the 
role of input frequency as a factor in explaining the errors produced in the IL (e.g., Cardoso, 2008; Cardoso, John \& French, 2009; Cardoso \& Liakin, 2009). Therefore, the current study will consider input frequency as a potential factor affecting L2 cluster acquisition in addition to markedness constraints and interlanguage transfer as constrained by the SSP.

Most of the studies on the L2 acquisition of the initial clusters in the literature have only looked at \#sC clusters (e.g., Carlisle, 1991, 1994, 2006; Someillan \& Yavaş, 2005; Yavaş \& Barlow, 2006; Cardoso, 2008; Cardoso, John \& French, 2008; Cardoso \& Liakin, 2009), with only few studies that included non \#sC clusters (e.g., Broselow, 1983, 1992; Eckman \& Iverson, 1994). Further, these studies usually reported that some participants employed epenthesis or prothesis as a process for cluster simplification. However, none of them have dealt with the question whether markedness or frequency of the cluster had an impact on the acoustics of the inserted vowel.

Therefore, this thesis investigates the production of 17 English initial double onsets by Saudi Arabian participants from two proficiency levels: intermediate and advanced. Specifically, it explores the order in which different initial consonant clusters are acquired. Further, it acoustically examines the error pattern employed by the participants. In the analysis of the data, this study applies a markedness approach based on sonority in order to account for the acquisition order and the error pattern. It also explores the possible impact of frequency of the input. However, the hypotheses of this study will be made solely from the perspective of markedness theory based on the SSP. The examination of the possible effects of input frequency will be an exploratory analysis only. 
The remainder of this chapter is devoted to introducing the organization of the following chapters. Chapter 2 introduces the concept of interlanguage phonology and provides explanations for key concepts including L1 transfer, markedness based on sonority, and frequency of input with a survey of relevant literature in order to help conceptualizing the purposes of the current study. It also presents the theoretical framework adopted for the markedness approach, namely the Ontogeny Phylogeny Model (OPM) (Major, 2001). Chapter 2 concludes with a brief description of English and Arabic syllable phonotactics, followed by the research questions and the hypotheses of this study.

Chapter 3 is dedicated for the research design and methodology employed in this study. It starts by introducing the participant groups, the method of selection and the stimulus materials. It also provides a detailed description of the procedures and the acoustical measurements. Finally, it explains the methods of analyses for both approaches markedness and input frequency. Chapter 4 presents the results and the related discussion. This chapter discusses application of different approaches and comments on the acquisition order of the clusters. It also discusses in details the error pattern observed. Chapter 4 concludes with a summary of the major findings. Chapter 5, the last chapter of this thesis, provides a general discussion and conclusions of the current study. It addresses the limitations of the current study and provides recommendations for future research. 


\section{CHAPTER 2. Literature Review}

\subsection{Interlanguage Phonology:}

The second language (L2) learner's linguistic system is considered different from both the first language (L1) and the L2, yet linked to them (Tarone, 1988). Selinker (1972) noted that the L2 learners' linguistic system is a result of the learner's attempt to produce native-like forms in the L2 during the acquisition process and it is a separate system from the L1 and the L2, a system that is mostly referred to as "interlanguage" (IL) (Selinker, 1972). The IL was introduced to account for the linguistic system of the adult L2 learners (Corder, 1981). Thus, IL can be defined as, the productions by non-native speakers of a given language during the development process of their linguistic system (Selinker, 1972; Major, 2001).

As mentioned in the previous chapter, the production errors made by L2 learners are mostly attributed to differences between the L1 and the L2. Numerous researchers have suggested that L1 transfer is the most common explanation for many erroneous or non-native productions (e.g., Lado, 1957; Selinker, 1972; Odlin, 1989). Transfer will be discussed in details in section (2.1) below, but for now the focus will be shifted to the components of the IL system. Not every error found in the IL can be attributed to transfer from the L1; some errors can be better explained by universal tendencies. In other words, universal tendencies come in play when there are elements in the IL that can be attributed to neither the L1 nor the L2 (Major, 2001).

Thus, the IL system is combination of three components: elements from the L1

(i.e., L1 transfer), elements from the L2 and universal elements that are not already found 
in the L1 and the L2 (Corder, 1971, 1981; Major, 2001). Figure 1.1.a below shows the three components of the IL as presented by Major (2001).

Figure 1.1.a Components of the Interlanguage System (Major, 2001. Foreign Accents: The Ontogeny Phylogeny Model)

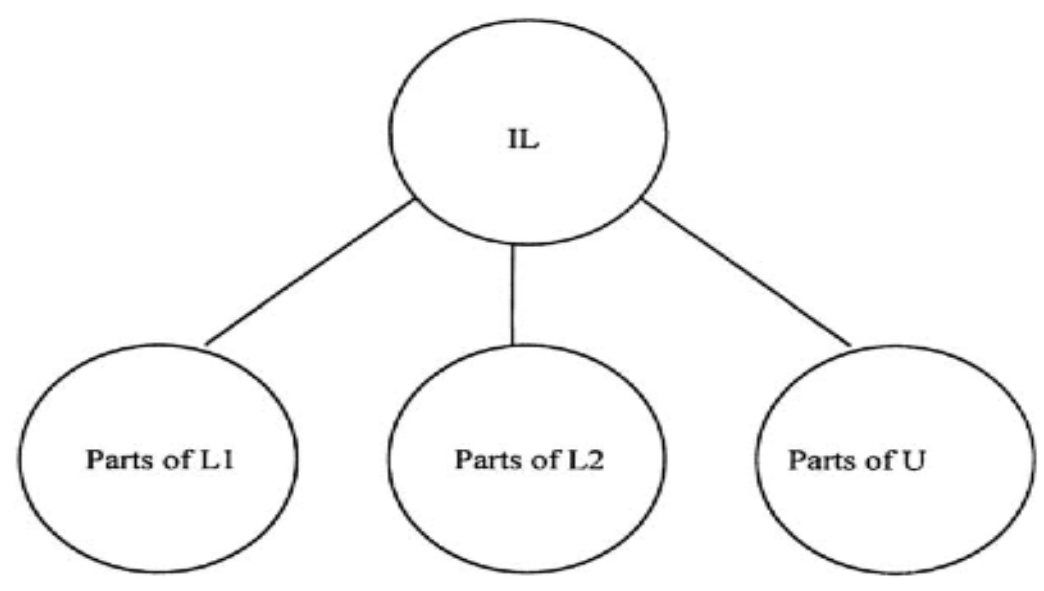

According to Major (2001), there are debates and discussions about how to characterize the IL system are unsettled. Questions include, does the IL development share characteristics of the $\mathrm{L} 1$ development? Can we regard IL as a natural language and that it follows the natural languages principles? (Major, 2001).

In general, the literature shows that IL system is regarded as a natural language. According to Adjemian (1976) interlanguage systems are considered natural languages because natural languages are systematic in the sense that they follow universals and have linguistic phenomena that are shared by them, such as phonological patterns, which is also true for IL systems. This claim was supported by number of researchers (e.g., Corder, 1981; Eckman, 1981, 1991, 1996) who concluded that IL systems are, in fact, natural language because they behave the same way. In addition to being systematic, the 
IL system has also been characterized as being permeable and dynamic (cf. Major, 2001). Permeability is a feature of natural languages because the rules shaping the knowledge of L1 are not set, but rather subject to alternation (Adjemian, 1976). This is also applicable to the IL system and therefore is characterized as being permeable. Further, the IL system is also dynamic given its constant change (Adjemian, 1976). It is important to note, however, that change in the IL system is often slow and steady (Ellis, 1985; Corder, 1981; Selinker, 1972).

\subsubsection{Transfer and The Contrastive Analysis Hypothesis:}

The notion of IL was originally associated with the Contrastive Analysis Hypothesis (CAH). The Contrastive Analysis Hypothesis explained learners' errors on the basis of the differences between the L1 and the L2 and predicted the errors and the areas of difficulty on the same basis (Lado, 1957; 1964). However, for reasons such as the inability to predict some errors made by learners, and an inability to predict what should be more difficult for $\mathrm{L} 2$ learners, the $\mathrm{CAH}$ has failed to explain everything that goes on in L2 learning (cf. Eckman, 2008; Major 2008). Since CAH was not able to provide explanations for all linguistic phenomena, researchers have stopped relying on it, and instead they have developed other theories and frameworks, as will be discussed in the subsequent section.

The term "transfer" refers to the process in which rules or linguistic elements from the L1 are transferred to the L2 (Andersen, 1983; Corder, 1992). There are two types of transfer: positive transfer and negative transfer. When the transferred phenomena from the L1 to the L2 are different, errors occur and this is called negative transfer. On 
the other hand, positive transfer occurs when transferred phenomena from the L1 to the L2 are similar, resulting in native-like productions (cf. Major, 2001, 2008; Corder, 1992).

Transfer has played an important role in the study of SLA generally, and in the study of L2 phonological acquisition specifically, dating back to Lado's major work in 1957 and even before that (cf. Fries 1945; Weinreich 1953).

Early studies on transfer (Fries 1945; Weinreich 1953; Lado, 1957), which typically considered transfer to be the explanation for all errors, were essential to the development of the CAH. Simply stated, CAH claimed that L2 similar phenomena to the L1 are easier to acquire and different phenomena are harder to acquire. The CAH predicted errors in the IL phonology by looking at the areas of differences between the L1 and the L2. In this framework (i.e., CAH) the interference or transfer solely explained the errors produced by the learners in the L2. According to Weinreich (1953) there are many different types of transfer as outlined below.

The first type is the learner's substitution of an L2 sound with the closest sound in his/her L1 inventory (ex. an Arabic L2 learner of English substitutes the English [p] with the Arabic [b] because Arabic does not have the voiceless bilabial stop). The second type of transfer is concerned with the phonological processes. It refers to allophonic processes such as the transfer of Arabic light /1/ (like the Spanish /1/) to replace the English dark /1/. Allophonic processes refer to two or more sounds that are variants of a single phoneme. The allophonic sounds are not contrastive and they do not change the meaning of the word. The third type is under-differentiation transfer, which occurs when the L2 draw a distinction between two sounds that is not drawn in the L1. Over-differentiation is the fourth type of transfer, which occurs when the L1 makes a distinction between two 
sounds but the L2 does not. A fifth type is the reinterpretation of distinctions or transferring distinctions from the L1 to the L2. The sixth type of transfer is the phonotactic interference. This type of transfer occurs when the learner transfers the syllable structure from the L1 to the L2 or when the L2 syllable structure is modified to conform with the L1 syllable structure constraints. Finally, the seventh type of transfer is prosodic interference. This occurs when, for instance, tone, stress or intonation patterns are transferred from the L1 to the L2.

In short, the CAH claimed that all errors could be predicted and explained by transfer. This claim, however, was soon criticized when many learners did not make the errors predicted by the CAH. In order to address this shortcoming, Wardhaugh (1970) suggested strong and weak versions of the CAH. According to Wardhaugh, the strong version was responsible for predicting the errors before they happened and the weak version was responsible for explaining the errors after they happened. Another shortcoming of the CAH was its inability to predict the degree of difficulty in the areas identified as problematic for the learners. In order to account for that Oller and Ziahosseiny's (1970) introduced a moderate version of CAH. In their moderate version, they claimed that the more similar the structures in L1 and L2, the more difficult learning would be. In other words, similar forms would be more difficult to acquire than different forms. With the shortcomings of the $\mathrm{CAH}$ and the growing awareness among researchers that transfer was not the only reason for errors in the L2, the research on transfer using CAH seemed to be abandoned during the 1970s. Selinker (1972), for instance, discussed that transfer is only one factor of many factors forming the IL system. 
Recently, however, a growing body of literature started to discuss the importance of transfer as a contributive factor to the field of SLA along side with other factors such as universals (Broselow 1984; Eckman \& Iverson 1994; Gass \& Selinker 1983, 1992; Han 2004; Han \& Odlin 2006; Kellerman \& Sharwood Smith 1986; Odlin 1989, 2003)

\subsubsection{Markedness in Interlanguage Phonology:}

Although, many errors found in the IL system could be explained through transfer, L1 transfer could not explain everything. Eckman (1977) argued that some aspects of the IL phonology might be attributed to the "complexity" or markedness of the structures. The introduction of Eckman's comments has been the start of an ongoing research in the field of Second Language Acquisition (SLA) in order to address important questions regarding the IL phonology. Both transfer and markedness of structures has been interesting subject of inquiry for researchers in the study of IL phonology and SLA.

Markedness has played a significant role in IL phonology research especially since the introduction of the two well-known hypotheses dealing with the L2 phonology both proposed by Eckman, namely, the Markedness Differential Hypothesis (MDH) (1977) and the Structural Conformity Hypothesis (SCH) (1991). For our purposes, a brief discussion of both of them is provided below.

\subsubsection{Markedness Differential Hypothesis:}

The CAH aimed to predict and explain the learners' areas of difficulty in the L2 only by comparing and contrasting the L1 and the L2. According to Eckman (1977), the incorporation of the MDH into the analysis of L2 errors is very important. Within the areas of differences between the L1 and the L2, Eckman claimed, marked structures are going to be more difficult than the unmarked counterparts. On one hand, different forms 
that are not universally marked are not difficult to be learned. On the other hand, different forms that are universally marked are expected to cause difficulty and the degrees of difficulty among marked forms are determined by the degree of markedness (Eckman, 1977).

One might ask what does "marked" means then? Eckman (1985) defined it as:

"A phenomenon or structure $\mathrm{X}$ in some languages is relatively more marked than some other phenomenon or structure $\mathrm{Y}$ if cross-linguistically the presence of $\mathrm{X}$ in a language implies the presence of $Y$, but the presence of $Y$ does not imply the presence of X.” (p. 290).

The MDH received support and number of studies have shown evidence of its validity (e.g., Anderson, 1987; Carlisle, 1991 among many others) Anderson (1987), for instance, studied the acquisition of the consonant clusters in English by subjects from different L1 backgrounds; namely Egyptian Arabic and two Chinese languages: Mandarin and Amoy. The results revealed that Egyptian Arabic speakers performed better than both Chinese groups in the coda clusters and their performance varied according to the degree of markedness of the clusters and how different the L1 is from the L2.

Another example supporting the MDH is from the productions of English complex onsets (\#sC(C) clusters) by native Spanish speakers, which were investigated by Carlisle (1991). Since Spanish is a language that does not allow initial \#sC clusters, which provides a great opportunity to investigate $\mathrm{AsC}_{\mathrm{s}}$ in the IL system. The results revealed that Spanish speakers tended to insert an epenthetic vowel to break up the disallowed clusters ( $\# \mathrm{sC}(\mathrm{C})$ clusters). Results also showed that participants modified more marked clusters more often than they did with less marked ones. According to 
markedness principles, there is a hierarchal order in which less marked clusters are expected be produced more correctly than more marked ones. Carlisle (1991) results showed such hierarchy and therefore provided support for the MDH.

Although MDH was able in addition to L1 transfer to explain most of the errors found in the IL, it focused only on the marked vs. unmarked structures that occurred in the areas of differences between the L1 and the L2. MDH made no predictions on structures that are found in both languages. This according to Eckman (1991, 1996, 2008) is considered a shortcoming of the hypothesis and, consequently, he introduced the Structural Conformity Hypothesis (1991).

\subsubsection{Structural Conformity Hypothesis (SCH):}

According to Eckman (1991), the Structural Conformity Hypothesis states " the universal generalizations that hold for primary languages hold also for interlanguages" (24). Eckman $(1991,1996,2008)$ argued that the SCH is motivated by L2 patterns, which are not found within the areas of differences between the L1 and the L2 and are related to markedness principles. In other words, the Markedness Differential Hypothesis was concerned with patterns, which are different within the L1-L2, but it did not address any errors outside the areas of differences. If the L2, for example, allow initial consonant clusters that are more complex (e.g., $\# \mathrm{sC}(\mathrm{C})$ clusters) than the ones found in the $\mathrm{L} 1$ (e.g., non \#sC clusters only), the learner's IL system is expected to adhere the universal constraints governing the clusters in the L2, studies of this sort have provided support for the SCH (e.g., Tarone, 1980; Carlisle, 1997, 1998; Eckman \& Iverson, 1993). In fact, Eckman (2008) stated that Markedness Differential Hypothesis assumptions could be easily accommodated within the SCH. According to Eckman (2008), SCH regards the IL 
systems as primary or natural languages at least in the way they "obey the same set of universal generations".

Prior studies could be easily explained through the $\mathrm{SCH}$ and subsequently the MDH since it is encompassed by SCH. In a study by Tarone (1980), English narratives by subjects from different L1s (Korean, Cantonese, and Portuguese) were transcribed. Results revealed that the subjects avoid producing the clusters by modifying $20 \%$ of the syllables; they modified the cluster through different strategies including epenthesis (insertion of a vowel), deletion (of one of the consonants in the cluster), or insertion of a consonant (usually a glottal stop). Although most of the modifications were attributed to L1 transfer, there were 30 instances unaccounted for by transfer. In these few instances Tarone interpreted them as a result of the universal preference for the CV syllable structure, because CV structure is the least marked syllable in the world's languages.

Two studies by Carlisle $(1997,1998)$, for instance, looked at the production of English consonant clusters by Spanish L2 learners of English. The purpose of these studies was to test the IL system of the subjects with the assumption that Spanish L2 learners of English would modify the consonant clusters that were more marked more than the clusters that were less marked based on the occurrence of the cluster in the language. Results from both studies supported his predictions and subsequently supported the Structural Conformity Hypothesis.

Eckman and Iverson (1993) also investigated the production of English complex codas by L1 speakers of three languages in which the complex codas are not permissible, namely Japanese, Korean and Cantonese. Although, errors were exhibited on a wide 
range, more errors were made in more marked codas than in less marked counterparts. This study yielded additional support for the SCH and the MDH.

\subsection{The Ontogeny Phylogeny Model (OPM):}

The Ontogeny Phylogeny Model (OPM) is a linguistic model created by Major (2001) to account for the development of the interlanguage system. Since the OPM is particularly concerned with the IL system it takes into consideration all of its three parts: L1, L2 and Universals (U), which are not already in the first or second language (Major, 2001).

There are four corollaries for the SLA within the OPM:

1- Chronological Corollary of the OPM

2- Stylistic Corollary of the OPM

3- Similarity Corollary of the OPM

4- Markedness Corollary of the OPM

A brief discussion of these four corollaries is in order.

\subsubsection{Chronological Corollary of The OPM:}

The Chronological Corollary of the OPM claims that the "IL develops chronologically in the following manner: L2 increases, L1 increases, and "Universals" increases and then decreases" (Major, 2001:85). At the early stages of the IL development, the L1 is dominant and very influential, which makes transfer most likely to take place. At these early stages, the influence of the L2 and universals are not evident. The L2 influence is not evident because the learner's knowledge is not yet sufficient to surface. As the acquisition process progresses, the L2 influence increases and continues to increase until the IL system is fully developed. The "universals" increases as the 
learner's IL develops and in later stages it decreases as the learner's knowledge of the L2 is getting stronger (see figure 2.1.a).

Figure 2.1.a the Ontogeny Phylogeny Model. Normal phenomena (Major, 2001. Foreign Accents: The Ontogeny Phylogeny Model $)^{1}$

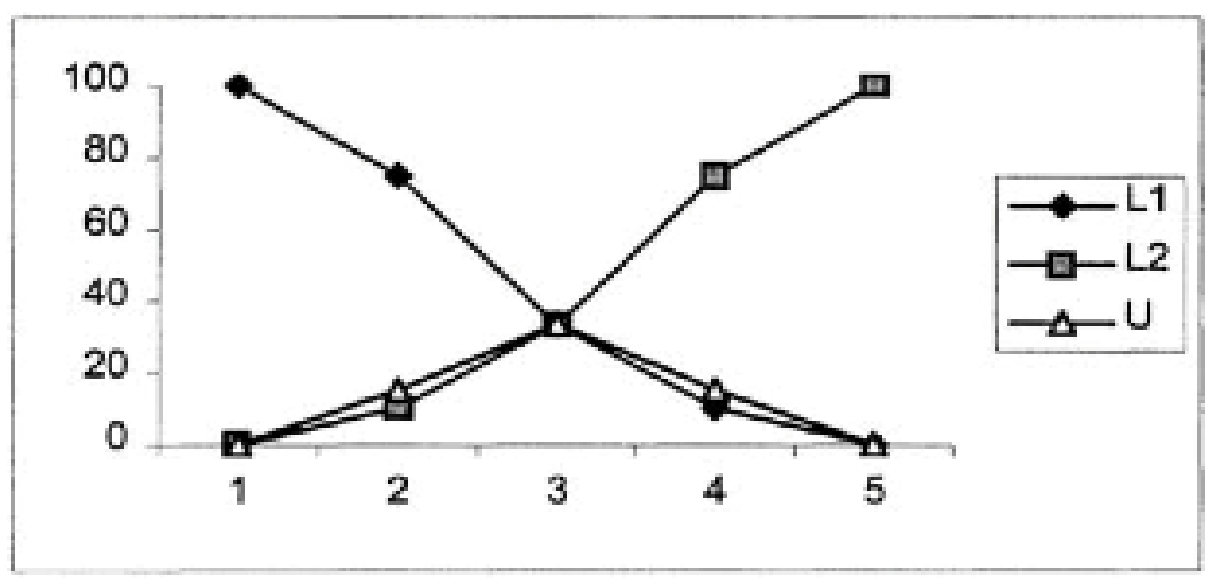

\subsubsection{Stylistic Corollary of The OPM:}

The Stylistic Corollary of the OPM maintains, in a general sense, the same manner as the chronology of the acquisition in that the IL starts with the L1 as the major (i.e., only) source of knowledge and decreases as L2 and U start to develop. The OPM makes the claim that as the influence of the $\mathrm{L} 1$ decreases, the $\mathrm{L} 2$ increases and the $\mathrm{U}$ both increases and decreases "as style becomes more formal" (Major, 2001:85). Specifically, as style becomes informal the influence of transfer becomes more dominant. The OPM notes, however, that the stylistic patterns can be upset by non-linguistic factors such as nervousness and inexperience of addressing audience, etc.

\footnotetext{
${ }^{1}$ The axis labels are percentages marking the levels of acquisition from $0-100 \%$
} 


\subsubsection{Similarity Corollary of The OPM:}

It has been claimed that similar phenomena between the L1 and the L2 are more difficult to be acquired than dissimilar or different phenomena (e.g., Ausubel, Novak, \& Hanesian, 1978; Andersen, 1983;). That is because it is harder to distinguish the small differences between two similar phenomena (Major, 2001). The OPM makes some predictions under what is called the Similarity Corollary. According to the OPM, in similar situations the parts of the IL develop in the following fashion: The L1 decreases slowly; the L2 increases slowly, the universals increases slowly and decreases slowly. The model highlights that the use of slowly refers to the development when we compare it to the development of the normal phenomena. Figure 2.1.b depicts the development of the IL parts in similar phenomena on a $100 \%$ scale.

Figure 2.1.b: The OPM, Similar phenomena (Major, 2001. Foreign Accents: The

\section{Ontogeny Phylogeny Model)}

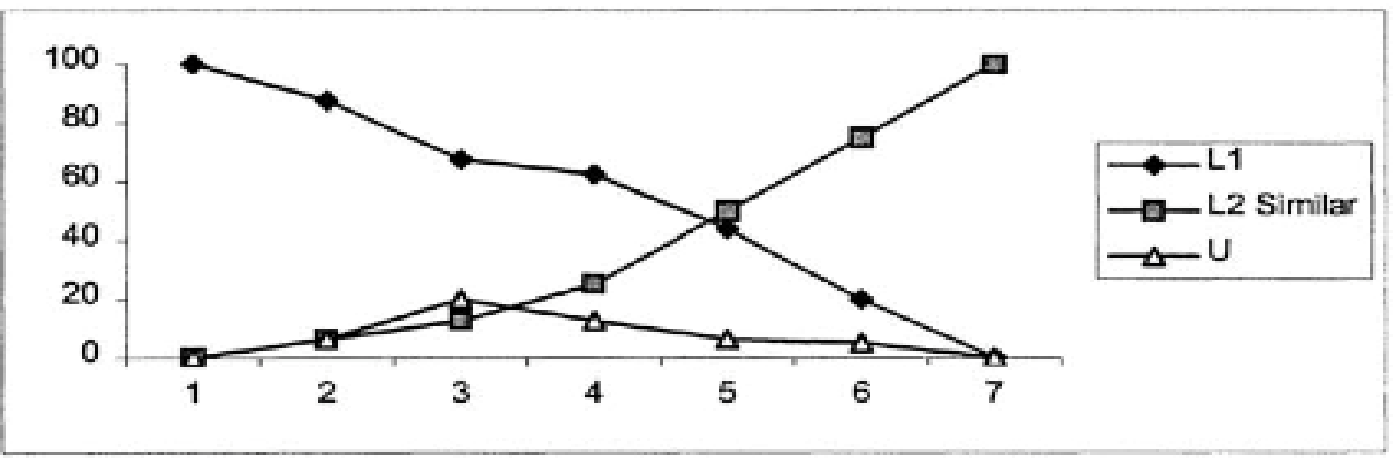

\subsubsection{Markedness Corollary of The OPM:}

The last corollary part that the OPM addresses is markedness. The model states that " in marked phenomena, IL develops chronologically in the following manner: (a) L2 increases slowly, (b) L1 decreases and then decreases slowly, and (c) U increases rapidly 
and then decreases slowly" (Major, 2001). Again, this model highlights that the use of slowly and rapidly means that the development is more slowly and more rapidly when we compare it to the development in the normal phenomena. The Markedness Corollary of the OPM shows that the universals play a greater role in the IL with more marked forms than less marked forms. This can be seen clearly after the earliest stages as it is depicted in figure 2.1.c below. The figure shows the $\mathrm{L} 2$ development stages $(1,2,3, \ldots$ etc. $)$ in the marked situations on a $100 \%$ scale, where $100 \%$ means completely developed.

Figure 2.1.c: The OPM. Marked phenomena. (Major, 2001. Foreign Accents: The

\section{Ontogeny Phylogeny Model)}

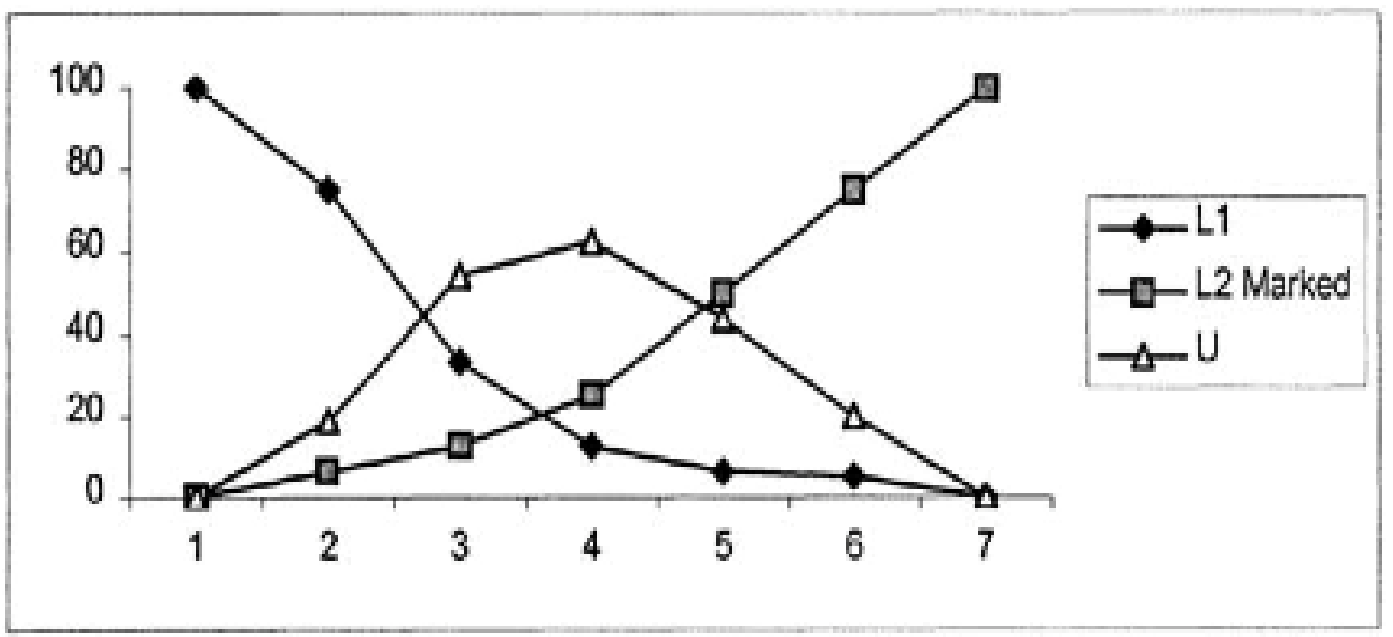

\subsection{Syllables:}

\subsubsection{Defining Syllables:}

A syllable is made of individual speech sounds or segments, in accordance to universal and language-specific phonetic and phonological rules (Yavaş, 2011). This section introduces syllables phonotactics in English and Arabic and analyzes the differences in light of sonority. 
Roach (2000) defined phonetic syllables as constituents with a "center". The center has minimal or no obstruction to the airflow and a comparative degree of loudness. What comes before and/or after the "center" will have greater obstruction to the airflow and/or less loudness. The English word "bat", for instance, is monosyllabic word (i.e., has only one syllable) where the vowel /æ/ occupies its center. In light of the definition above one can see that the vowel $/ \mathfrak{x} /$ is fulfilling the requirement of the center by being unobstructed and being louder than the other sounds surrounding it since the airflow streams of both $/ \mathrm{b} /$ and $/ \mathrm{t} /$ are fully obstructed and their degree of loudness is low.

The syllable is a phonologically complex unit consisting of one obligatory element, a vowel or a diphthong, occupying the nucleus $(\mathrm{N})$ position and optional marginal elements. The optional consonant segments surrounding the nucleus are defined according to their relation to the nucleus; consonants occurring before the nucleus are called onset $(\mathrm{O})$ and consonants occurring after the nucleus are called coda $(\mathrm{C})$ (Yavaş, 2011). Thus, there are different possible structures for the simple syllable as shown in Table 2 below:

Table 2: Representation of simple syllable structures

\begin{tabular}{c|c|c|c}
\hline $\mathrm{N} / \mathrm{v} /$ & $\mathrm{O}+\mathrm{N} / \mathrm{CV} /$ & $\mathrm{N}+\mathrm{C} / \mathrm{VC} /$ & $\mathrm{O}+\mathrm{N}+\mathrm{C} / \mathrm{CVC} /$ \\
\hline $\mathrm{a}[\mathrm{a}]$ & $\mathrm{me}[\mathrm{mI}]$ & in [m] & bat [bæt] \\
\hline
\end{tabular}

The syllable is marked by a small Greek sigma $(\sigma)$ and has two immediate constituents the onset $(\mathrm{O})$, which consists of the consonants preceding the vowel (nucleus) and the rhyme (R), which subsumes what comes after the onset -the nucleus $(\mathrm{N})$ and the coda (Co). Thus the rhyme will include the obligatory element in the syllable - the nucleus 
also known as the peak, which represents the most sonorous element. The coda position will include all consonants following the nucleus in a syllable (Yavaş, 2011). This means syllables can be represented with the following hierarchical structure:

Figure 3.1.a: Hierarchal Representation of the Syllable Structure (for the word "dog")

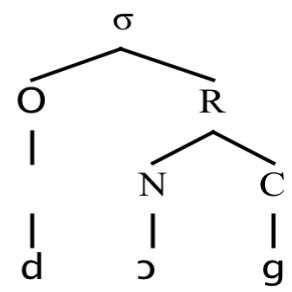

Based on the structure of the rhyme, the syllable is classified as open or closed syllable. Syllables with a consonant occupying the coda positions are "closed" syllables (e.g., "bat"/bæt/ and "in"/mn/), and syllables without codas are " open" syllables (e.g., "sea"/si:/).

When onsets or codas have more than one consonant (i.e., have string of consonants), they are labeled as complex onsets or complex codas. Since this thesis is not focusing on codas, only complex onsets will be discussed here. It is evident that less marked onsets are faster to be acquired when compared to marked ones (Eckman, 1991). Phonologists also discussed that the degree of markedness among complex onsets increases with length (Greenberg, 1978; Clements, 1990; Morelli, 2003). In other words double onsets (cluster with two consonants such as /pr/ in "prank") are less marked than triple onsets and triple onsets (clusters with three consonants such as /str/ in "street"). 
This was supported by number of studies in the L2 phonology (e.g., Carlisle 1997, 1998, 2002).

Carlisle $(1997,1998,2002)$ has examined the production of Spanish L1 speakers producing English onsets with different length in longitudinal studies. In all of the three studies, participants produced less marked ones (double onsets) more accurately than more marked ones (triple onsets). The results showed that markedness of the onsets influences the acquisition.

\subsubsection{Sonority Sequencing Principle (SSP):}

Sonority is widely used in determining the degree of relative markedness of structures; especially what sound sequences are permissible in a given language. The idea of sonority is well represented in the Sonority Sequencing Principle (SSP) which states that any syllable must contain a segment that constitutes its sonority peak preceded by a segment or a sequence of segments with increasing values of sonority and/or followed by segment or a sequence of segments with decreasing values of sonority (Selkirk, 1984). As mentioned earlier, since the interlanguage systems are like natural languages, we expect them to follow the SSP.

There is no unified definition for sonority in the literature and it seems rather controversial. Prince (1980) and Ladefoged (1993), for instance, defined sonority in terms of loudness of sounds. The loudness of sounds is related to their acoustic energy in relation to other sounds sharing the same length and supersegmentals (i.e., stress, pitch ... etc.). In other words, the saliency of a sound is defined in relation to its degree of sonority, whereby the higher the sonority is, the more salience the sound will be. Other scholars such as Keating (1983) and Lindblom (1993) defined sonority in relation to 
sounds' ease of articulation. However, for the purposes of this thesis, sonority can be defined as a group of phonological principles, which deals with the arrangement of segments into syllables. Therefore, the sonority of a sound is, as stated by Yavaş (2011), "primarily related to the degree of opening of the vocal tract during its articulation". Essentially, the more open the vocal tract is, the more sonorant a sound will be. Yavaş (2003, 2011) also noted that when two sounds have the same degree of sonority (i.e., same degree of vocal tract opening), then voicing comes relevant; the voiced sound will be greater in sonority than the voiceless one.

Although, there have been several sonority scales proposed by different researchers, there is an agreement among them on grouping the sounds according to their degree of sonority (Zec, 1995; Clements, 1990; Hogg and McCully, 1987). Hogg and McCully (1987) developed one of the most detailed sonority scales. In Hogg and McCully's (1987) 10-point scale, vowels are divided into low, mid, and high; also there is a distinction between laterals, and more detailed rankings for obstruents. The 10-point scale by Hogg and McCully (1987) is, generally, consistent with other scales but it gives detailed hierarchies, such as the distinction in voiced stops and fricative and voiceless stops and fricatives as shown in the table 1.

Sonority is very relevant to languages with consonant clusters either in the onsets or codas because there are certain constraints in terms of the sonority distance between the consonants in the cluster. It is a universal tendency that more natural sequence in a consonant cluster will be in clusters with a greater distance between the consonants in those clusters (Yavaş, 2003). For example, in double onset clusters situations, the focus of this thesis, /pr/ is a more natural onset than /fr/ because /p/ in /pr/ has a sonority index 
of 1 and /r/ has a sonority index of 7 allowing a greater sonority distance (6 sonority steps) between the first consonant $\mathrm{C} 1$ and the second consonant (C2). However, in /fr/ the sonority distance is smaller because /f/ has a sonority index of 3 and /r/ has a sonority index of 7 making the sonority difference smaller (4 sonority steps), and therefore, less natural. It is important to note, however, that there are some sequences that violates the SSP because they give "negative sonority" such as /st, sk, sp/ in the onset position. The violation takes place, here, because of sequencing towards the peak is going from higher sonority to lower sonority before the peak (Barlow, 2001; Yavaş, 2003, 2010).

In general, the discussion in the literature about SSP violations circulates around two interesting phenomena in /s/ clusters. First, some /s/ clusters violate the SSP in the sense that sonority drops as we proceed from $\mathrm{C} 1$ to $\mathrm{C} 2$ to the nucleus. This can be seen with /sp/, /st/, /sk/ in the following examples: spoon, steal, skin. Secondly, /s/ is the only sound in English that maybe followed by a nasal or a stop in the initial consonant cluster, this means a violation of the English phonotactics, which does not allow homorganic clusters (Barlow, 2001; Yavaş, 2003). Yavaş (2003) also highlights that English /s/ can also "co-occur with other coronals $(/ \mathrm{sn} /, / \mathrm{sl} /, / \mathrm{st} /)$, however those coronals that occurred with /s/ are not permitted with other homorganic clusters such as /bl/ and /d1/.

Given the different behaviors of /s/ clusters, researchers have suggested different approaches to account for the /s/ clusters. Some researchers have suggested a special 'adjunct' status for the /s/ clusters (Giegerich, 1992; Kenstowicz, 1994), others (e.g., Blevins, 1995) have argued that /s/ clusters are structurally the same as non /s/ cluster. Finally, others have argued for an approach that treats /s/ clusters as "string of complex segments" (Selkirk, 1984). Because this is particularly relevant to the results section, it 
will be further addressed in chapter 4 (see Clements \& Hume, 1995; Kenstowicz, 1994; Yavaş, 2003).

Previous research on the acquisition of consonant clusters provided support for the role of sonority from three different populations, namely, typically developing children learning their L1, children with speech disorders and adult L2 learners.

On the study of normally development children, Yavaş (2005) examined the acquisition pattern of double onsets /sC/ clusters by Spanish English bilingual children. Data was elicited via picture description task from 15 children in order to examine whether there is a difference in the behavior between $/ \mathrm{sC} /$ clusters following the $\mathrm{SSP}$ and /sC/ clusters violating the SSP. Although this study did not provide enough evidence for different behaviors in regard to the clusters following/ violating the SSP, it revealed that, in general, sonority distance between $\mathrm{C} 1$ and $\mathrm{C} 2$ are correlated with the percentages of correct production. Participants, generally, produced clusters with larger sonority distance between $\mathrm{C} 1$ and $\mathrm{C} 2$ with higher accuracy rates than clusters with smaller sonority distances.

Another study by Yavaş \& Barlow (2006) examined the production of /sC/ clusters by 40 Spanish English bilingual children. Results of their study further supported the role of sonority in the acquisition of initial clusters. Participants produced less marked clusters more accurately than more marked ones. The predicted pattern predicted by sonority and followed by the participants was as follows: /sw/ $>/ \mathrm{sl} />/ \mathrm{s}+$ nasal $/>$ /s+stop/.

Finally, Hefter (2012) conducted a longitudinal study examining the acquisition of initial English /sC/ clusters by one English speaking child. Data was collected via 
pseudo words elicitation, child directed speech and language observation journal. Results showed that the developmental path followed the sonority predictions. The participant was successful in producing and subsequently acquiring less marked clusters (i.e., /sl/ > /sn/) before more marked ones (i.e., /st/). The researcher also examined the role of input frequency, however, the input frequency predictions were not supported by the results.

Although the study of cluster acquisition by phonologically disordered population is not very common in the literature, some studies on children with speech disorders have provided support for the role of sonority on the acquisition of consonant clusters. In a study by Yavaş (2010), for example, thirty Spanish-English children with phonological disorders were evaluated in terms of their production of English $/ \mathrm{sC} /$ clusters. Results revealed that sonority was relevant to the study. Participants showed a hierarchy in their performance whereby less marked structures were produced more accurately than other clusters in the following order: $/ \mathrm{sw} />/ \mathrm{s} \mathrm{l} />/ \mathrm{s}+$ nasal $/>/ \mathrm{s}+\mathrm{stop} /$.

Another study by Yavaş \& McLeod (2010) examined the acquisition of initial $/ \mathrm{sC} /$ clusters in thirty English monolingual children with phonological disorders. One purpose of this study was to examine the role of SSP in explaining the cluster productions. Results revealed that participants followed the SSP prediction in that clusters with large sonority distance between $\mathrm{C} 1$ and $\mathrm{C} 2$ were produced with higher accuracy rates (i.e., $/ \mathrm{sw} />/ \mathrm{s} 1 />/ \mathrm{s}+$ nasal $/>/ \mathrm{s}+$ stop/).

Several studies in the IL phonology provide support for the role of sonority in the acquisition of L2 initial consonant clusters. In a study by Broselow and Finer (1991), they predicted that clusters with greater sonority would be easier to acquire than clusters with smaller sonority. In order to test their predictions, Broselow and Finer examined the 
production of English words with initial consonant clusters of two members (double onsets), namely /pr/, /br/, /fr/, /pj/, /bj/, and /fj/, from native speakers of Korean and Japanese. The results supported their predictions. Participants from both groups, for instance, modified /fr/ more than /pr/, which follows what sonority sequencing says about the natural hierarchy relation among members in the cluster.

Abrahamsson (1999) tested the production of Swedish /sC/ sequences, namely /s+nasal/, /s+stop/ and /s+lateral/ by Spanish L1 speakers. While Swedish allows initial/sC/ sequences, Spanish does not have them. Therefore, it is expected that Spanish L2 learners of Swedish would have difficulty producing these clusters and their performance would vary according to the different degrees of markedness. The results from Abrahamsson's study revealed that participants produced /s+nasal/ most accurately followed by $/ \mathrm{s}+$ stop/ clusters and finally $/ \mathrm{s}+$ lateral/ with least accuracy rate. According to the sonority predictions, it is expected to see the following order (where $>$ means more accurate) $/ \mathrm{sl} />/ \mathrm{s}+$ nasal $/>/ \mathrm{s}+$ stop/. Therefore, this study yielded partial support for the role of sonority.

Carlisle (1988, 1991, 1992, 1994, 1997, 2006) examined the acquisition of some English onsets, /sl, s+nasal, s+stop/, by speakers of Spanish, a language that disallow initial /s/ clusters. Generally, it was expected that these clusters would be problematic for Spanish speakers learning English. The results from different studies showed that /sl/ clusters were most accurate ones that participants produced, followed by $/ \mathrm{s}+$ nasal/. $/ \mathrm{s}+$ stop/ clusters were the most problematic ones. Since Spanish does not allow such clusters, transfer could not explain the errors, but rather the sonority sequencing principle provided an explanation for that. The violation of SSP in $/ \mathrm{s}+\mathrm{stop} /$ clusters is because of 
the "falling sonority" these clusters have, such violation is not found the remaining two clusters $/ \mathrm{sl} /$ and /s+nasal/ because they show a "rising sonority". The results of this study supported the predictions that participants will perform better in less marked clusters ( $\mathrm{s}+$ nasal/ and /s+lateral/) than they do is more marked clusters such as $/ \mathrm{s}+\mathrm{stop} /$.

Rauber (2006) examined the production of English initial /sl, s+nasal, s+stop/ by native speakers of Brazilian Portuguese and Argentine Spanish. Results showed that participants from both native languages inserted prothetic vowel before the clusters. The instances of inserting the prothetic vowel were more with clusters violating the SSP than they were with clusters following the SSP. The results yielded support for the role of sonority because more marked clusters were modified more than less marked clusters. In fact the order in which clusters were produced was the same order predicted by sonority (i.e., $/ \mathrm{sl} />/ \mathrm{s}+$ nasal $/>/ \mathrm{s}+$ stop/).

Cardoso and Liakin (2009) examined the production of English initial consonant clusters (/st, sl/sn/) by 10 Brazilian Portuguese native speakers from two levels: lowintermediate and advanced. Cardoso and Liakin's predictions were based on the markedness of the cluster based on sonority. Results came in line with Carlisle results, cited above, in that the /st/ cluster was the most difficult to acquire, the /sn/ was less difficult and finally /s1/ was the least difficult because it has the perfect sonority distance between $\mathrm{C} 1$ and $\mathrm{C} 2$.

Hansen-Edwards (in press) explored the role of markedness by sonority, L1 transfer and input frequency in the acquisition of three English double onsets, /sl, sn, st/, by native speakers of Mandarin, Vietnamese and Cantonese. While results from Cantonese and Mandarin L1 speakers provided support for L1 transfer and input 
frequency respectively, results from Vietnamese L1 speakers supported the role of sonority. Vietnamese L1 speakers produced both /sl/ and /sn/ clusters with $100 \%$ accuracy rate and /st/ with only $84 \%$ accurate productions. The fact that less marked structures were produced with higher accuracy rate than more marked one suggested that markedness by sonority has greater impact on the acquisition than L1 transfer or input frequency.

\subsection{Role of Input Frequency in Clusters Acquisition:}

With the growing body of literature on the production of consonant clusters, transfer and universals tendencies seem to explain most of the error patterns found in the IL phonology (cf. Eckman, 2008). Another approach that seems influential in explaining errors produced by children learning their L1 is the role of input frequency (Zamuner, Gerken, \& Hammond, 2005). The idea is that children will acquire more frequently marked forms before they acquire the infrequent unmarked ones. However, the role of input frequency in the acquisition of consonant clusters in the L2 is considered relatively new.

Few studies in the literature have examined at the role of input frequency as a factor in explaining the errors produced in the IL. In a study by Cardoso (2008), three clusters /sl, sn, st/ were examined to determine whether the frequency of the input or the markedness is actually able to explain the errors in the IL. The results showed that markedness was able to explain the errors and not frequency of input.

In many of the studies on the production of English /s/ clusters by Spanish L1 speakers by Carlisle, some reviewed above, $(1988,1991,1994,1997,2006)$, reported that more errors have been done on longer clusters (triple onsets). Also, the markedness of the 
/s/ cluster based on sonority seemed to explain the error patterns. Carlisle reported that /sl/ was the most accurate cluster among /sl, $\mathrm{s}+$ nasal, $\mathrm{s}+\mathrm{stop} /$ and $\mathrm{s}+$ stop was the more marked one and therefore with the most modifications. This, of course, provides evidence against the input frequency.

In two studies by Cardoso (2008) and Cardoso and Liakin (2009), researchers looked at the English /st, sn, sl/ clusters produced by Brazilian Portuguese speakers, the researchers examined the role of sonority and the role of input frequency. The sonority predicted that participants will be most successful in producing /sl/ because it is the least marked cluster among the three, followed by /sn/ (more marked) and then /st/ because it is the most marked among all. Input frequency predicted, that although /st/ cluster is the most marked cluster; it is more common than the other two clusters, therefore, participants will acquire it before the other two clusters. Further it states that $/ \mathrm{sn} /$ is the second most common and /sl/ is the least common, making the opposite hierarchal pattern predicted by sonority. Results from these studies provided support for the predictions based on sonority. However, Cardoso, John and French (2009) argued that input frequency has a stronger influence than sonority on the participants' ability to discriminate consonant clusters, which according to them, provided support for the input frequency explanation for the developmental order of consonant cluster in the L2. Another study by Hansen-Edwards (in press) showed that production of English initial clusters /sl, sn, st/ by L1 speakers of Mandarin is best explained by input frequency. Mandarin speakers produced English /st/ with highest accuracy rate followed by $/ \mathrm{sl} /$ and then $/ \mathrm{sn} /$. The $/ \mathrm{st} />/ \mathrm{sl} />/ \mathrm{sn} /$ order is in contrast to what sonority would predict and therefore input frequency provided the best explanation for the results. 
The studies on the L2 surveyed above did not show much influence from input frequency. On the other hand, markedness based on sonority seemed to better explain the order of accuracy in the target clusters. With the growing interest in the input frequency approach in the L2, especially after it became evident in the children L1 acquisition, it is worthwhile to examine this phenomenon further.

\subsection{Studies on Onset Cluster Produced by Arabic L2 Learners of English:}

The majority of the studies on the initial clusters are focused on the $/ \mathrm{s} / \mathrm{clusters}$. Moreover, the vast majority of the research examines L1 Spanish and Portuguese speakers producing clusters in L2 English. Since, the primary interest of this thesis is looking at the English initial double onset of both /s/ and non /s/ clusters produced by Saudi Arabic L1 speakers, this subsection is devoted to reviewing the relevant pieces of literature on Arabic.

Unfortunately, the study of English cluster acquisition by Arabic L1 speakers is underrepresented. There do not seem, to be many studies investigating Saudi Arabic. However, there are some works examining Egyptian Arabic and Iraqi Arabic, which to some extent share a lot of phonotactic features with Saudi Arabic.

Broselow $(1983 ; 1992)$ studied the acquisition of the English consonant clusters by L1 Arabic speakers from two different varieties of Arabic; namely Iraqi and Egyptian Arabic. She observed discrepancies in the ways speakers of the two varieties handle their pronunciation of English initial consonant clusters (at the beginning of the word) such as /p1/ and /fl/ in (play) and (floor) respectively. According to Broselow, native speakers of Egyptian Arabic tend to insert an epenthetic vowel [i] (between the two consonants in the initial consonant clusters exemplified in "[pilay] 'play"”). Although native Iraqi speakers 
generally made fewer errors in the initial consonant clusters, their errors revealed an insertion of a prothetic [i] (before the initial cluster example "[ifloor]"). Broselow (1992) argued that both insertion behaviors are attributed to the adoption or transfer of some phonological rules from the native language that prevents consonants to cluster in the word initial to ease their pronunciation in English. In Egyptian Arabic words may only start with one consonant. Hence, the insertion of the /i/ between the two consonants by Egyptian speakers "served to bring the English words into conformity with Egyptian syllable structure constraints" (Broselow, 1992). Iraqi speakers had less difficulty dealing with initial consonant clusters, which, according to Broselow, can be attributed to "positive transfer". Broselow further explained that since some Iraqi words may begin with consonant clusters where the vowel [i] may be optionally dropped before the initial cluster to give two alternate forms, like in the Iraqi word for "dogs" /iklaab/ or /klaab/, this phonological rule from the L1 was a clear example of transfer to the L2.

\subsection{Syllable Phonotactics}

\subsubsection{English Syllable Phonotactics:}

English is flexible in the syllable structures that it allows. It has only one obligatory element, which is the nucleus, surrounded by optional elements. In the onset position English allows up to three consonants. That it is to say in English, the onset position can be occupied by one consonant (single onset as in "man"), two consonants (double onset as in "plan") or three consonants (triple onsets as in "street"). The same can be said for the coda position; English allows single, double, and triple codas. In the coda position with suffixes four consonants could be found (Yavaş, 2011). Although this thesis will 
only be dealing with double onsets, here are the possible structures that are found in English, where "( )" means optional:

$$
\text { (C) (C) (C) V (C) (C) (C) }
$$

There are few restrictions on the consonants that are allowed to occupy the first consonant position and the second consonant position in English double (Yavaş, 2011). The Table 3 below shows possible English double onsets:

Table 3: Possible English double onsets (Yavaş, 2011. Applied English Phonology)

\begin{tabular}{|c|c|c|c|c|c|c|c|c|c|c|}
\hline & P & $t$ & $\mathrm{k}$ & $\mathrm{f}$ & $\mathrm{m}$ & $\mathrm{n}$ & 1 & 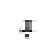 & $\mathrm{w}$ & j \\
\hline P & v & & & & & & $\checkmark$ & 2 & & $\nu$ \\
\hline b & & & & & & & $\sim$ & $\checkmark$ & & $r$ \\
\hline$t$ & & E & & & & & & $r$ & $\sigma$ & $(\boldsymbol{\sim})$ \\
\hline d & & & & & & & & $\checkmark$ & $\sigma$ & ( $\boldsymbol{\sim})$ \\
\hline k & & & a & & & & $\checkmark$ & $\checkmark$ & $\sigma$ & $\checkmark$ \\
\hline $\mathrm{g}$ & & & & & & & 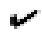 & $\checkmark$ & $\alpha$ & \\
\hline $\mathrm{f}$ & & & & - & & & 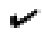 & 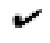 & & 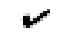 \\
\hline $\mathrm{v}$ & & & & & & & & & & $\sigma$ \\
\hline$\theta$ & & & & & & & & $\checkmark$ & $\sigma$ & \\
\hline$s$ & $\checkmark$ & 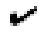 & 2 & $\sim$ & $\sim$ & $\sim$ & $\checkmark$ & & $\alpha$ & ( $\boldsymbol{\sim})$ \\
\hline$f$ & & & & & & & & $\checkmark$ & & \\
\hline h & & & & & & & & & & $v$ \\
\hline $\mathrm{m}$ & & & & & $\boldsymbol{\square}$ & & & & & $\sigma$ \\
\hline $\mathrm{n}$ & & & & & & - & & & & $(\boldsymbol{\sim})$ \\
\hline 1 & & & & & & & = & & & ( $\boldsymbol{\sim})$ \\
\hline
\end{tabular}

Notes:

$\sim$ Double onsets that are allowed in English

( $\sim$ ) Double onsets that are not found for most speakers of American English

- Impossible combination

\subsubsection{Arabic Syllable Phonotactics:}

Modern Standard Arabic (hereafter MSA) is the official language of Saudi Arabia. It is the language of education, media, and politics. There are no native speakers 
of MSA. As it is the case with any language, there are many verities of MSA, such as Egyptian Arabic, Moroccan Arabic, Iraqi Arabic, and Saudi Arabic. Saudi Arabic is will be the focus of this section.

Although there are very limited resources on the Saudi Arabic (SA) syllable structure and phonotactics, there are some related pieces of work in the literature. Saudi Arabic follows the MSA syllable structure. Therefore, there are some generalizations supported by the literature that can be drawn about SA:

a) As it is the case for MSA and many other Arabic varieties such as Egyptian Arabic, Saudi Arabic does not allow complex onsets (McCarthy, 2005; Archibald, 2003; Gafos, 2003; Edzard, 2000; Haddad, 2005).

b) Saudi Arabic does not allow words to start with a vowel. In other words, every syllable initial must start with a consonant; in some instances this process is done through borrowing a consonant from a previous word in what is known as elision (McCarthy, 2005; Haddad, 2005; Gadoua, 2000; Carter, 2004).

c) The geminates are not allowed initially in Saudi Arabic. The term "geminates" refers to the consonants that have twice the duration of their single counterpart, for illustration purposes this can be observed in the following durational contrast in the /k/ sound between "black king" vs. "blacking". Although, in Arabic geminates are allowed word medial and final, they do not occur initially; otherwise, it will form a complex onset (Gafos, 2003).

MSA has both open and closed syllables, forming the following possible syllable structures: Open CV, CV: and closed CVC, CV:C, or CVCC (Kaye, 2009). This is exactly the case for Saudi Arabic and as shown neither MSA nor Saudi Arabic allow 
complex onsets. Therefore, the following examples represent the different possible syllable structures found in Saudi Arabic:

Figure 4.1 (a,b,c,d,e): Possible syllable structures in Arabic
a) $/ \mathrm{ma} /$ (water) "maa"2
b) /fi:/ (in) "fee"
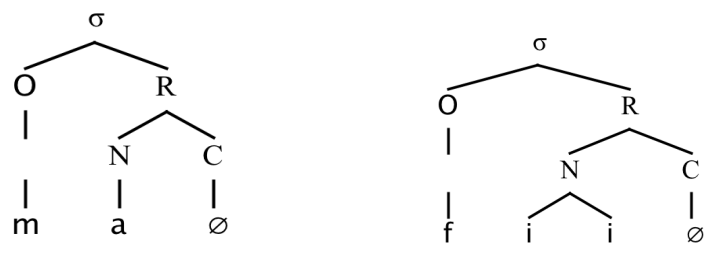

c) $/ \mathrm{min} /$ (from) “men"

d) /mi:n/ (who is?) "mean"
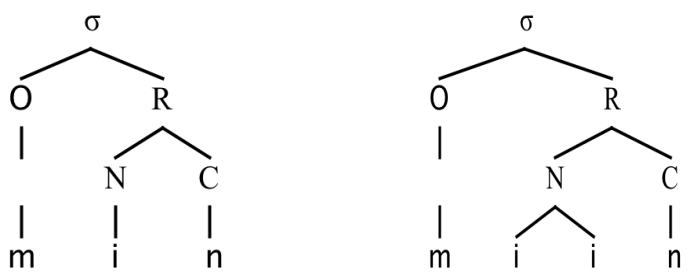

e) /kalb/ (dog) "kalb"

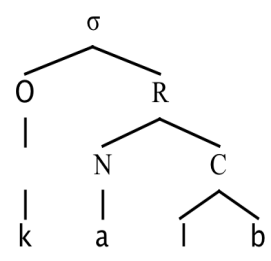

\footnotetext{
${ }^{2}$ The quotation marks ("") contains the English gloss for the words
} 


\subsection{The Current Study:}

We have seen that English allows complex syllable structures (i.e., consonant clusters), with only one obligatory element, which is a vowel or a diphthong, occupying the nucleus position and optional consonants surrounding that vowel from either or both sides $($ ex. print $=$ CCVCC $)($ Yavaş, 2011). While English allows both complex onsets and codas, this thesis is primarily concerned with the initial consonant clusters containing two members (ex. praise). In stark contrast to English, as this chapter shows, Saudi Arabic does not allow words to start with consonant clusters. In Saudi Arabic it is only permissible to have one consonant at the beginning of the word followed by a vowel to form a simple syllable structure like CV (Abu-Mansour, 1987). Given that English is very rich with complex syllable structures while Saudi Arabic is not, one can expect that Saudi Arabic speakers who are learning English as their L2 will have difficulty producing complex structures that are not allowed in their L1. The nature of the consonant clusters acquisition's problem and the source of the difficulty is what this thesis aims to explore.

The objective of this thesis, then, is to determine "how do Saudi L2 learners of English treat initial consonant clusters given that such clusters are not allowed in their L1?". In order to test the production of the clusters, participants are presented with English sentences and are observed to determine the nature of their productions and to identify what are the sources of errors? Sonority is helpful in organizing clusters based on their relative degrees of markedness. Therefore, there are number of hypotheses for the current study:

a) Saudi L2 speakers of English will have difficulty producing English initial consonant clusters in general. 
b) The degree of difficulty will vary according the markedness (based on sonority distances between the first consonant and the second consonant of the clusters.

c) Advanced participants will perform better than intermediate participants.

d) Saudi L2 speakers of English are likely to insert a prothetic vowel to simplify the clusters.

e) The duration of the prothetic vowel will be determined by the degree of markedness of the clusters (based on sonority); the greater the sonority distance between $\mathrm{C} 1$ and $\mathrm{C} 2$ the shorter the prothetic vowel will be, and the vowel will get longer as the sonority distances get smaller.

f) Intermediate participants will tend to insert longer prothetic vowel than advanced participants. 


\section{CHAPTER 3. Research Design and Methodology}

The previous chapter identified a significant gap in the literature in regard to the production of consonant clusters by Saudi L2 learners of English. The fact that initial complex consonant clusters are not permissible in Saudi Arabic provides a great research opportunity to test how language-specific phonological constrains interact with the speaker's L1 and universal principles.

The present study obtained data from L2 speakers who were living in a country where their L2 is spoken dominantly, which means that they were in constant contact with English. The participants were from two different levels of proficiency. Participants in the first group were selected from an intermediate level and were expected to have more difficulty in the overall because of their lack of experience in their L2. Participants in the second group were selected from more experienced and more proficient learners. Participants in the second group (i.e., advanced) were expected to have less difficulty in producing complex clusters than participants in the intermediate group given their more experience, but they were expected to exhibit some difficulties nevertheless.

In order to perform a quantitative analysis of the patterns in complex clusters production, it was necessary to have a recorded data containing the target clusters from participants. In order to control for any L1 dialectal variation, which might interfere with data in this study, this study limited its participants to Saudi Arabians only. Therefore, the overall purpose of this investigation is to examine patterns in which L2 intermediate and advanced participants produce complex consonant clusters. 


\subsection{Participants:}

This thesis aims to examine the production of the English double onsets by Saudi Arabian L2 learners of English. In order to collect data from a representative sample, forty-six Saudi participants (22 females, 24 males) in Miami were recruited to participate in this study. The sample mainly consisted of ESL and university students. The recruitment passed through two phases: 1) screening for potential participants and 2) the recruitment phase. In the screening phase, the researcher distributed an informational letter among Saudi students at Florida International University, and people who were interested in participating contacted the researcher. The researcher then met individually with them and obtained preliminary information through a language background questionnaire (Appendix A). After analyzing the information in the language history questionnaire, potential participants were then categorized into two groups according to their level of English: intermediate and advanced. Key criteria included being born and raised in Saudi Arabia and speaking Arabic natively: English had to be an L2 and learning English had to begin after arrival in the United States.

The intermediate group consisted of 23 participants (13 females and 10 males). Their mean age was 21.8 (range 19-25). They all reported to be enrolled in ESL classes at the time of testing. They reported to using their L1 predominantly on a daily basis (more than $70.0 \%$ of the time) including speaking to friends and family. Their English usage was merely limited to school and shopping interactions. The mean percentage of their reported estimate English daily usage was 26.3\%. Participants rated themselves no higher than 4 on a 7-point Likert scale regarding their English competence with a mean score of 3 
The advanced group consisted of 23 participants ( 9 females and 14 males). Their mean age was 21.8 (range 19-25). They all reported to be enrolled in university undergraduate classes at Florida International University at the time of testing. They reported to use English predominantly on a daily basis ( $75.4 \%$ of the time) including speaking to friends and some family members. Their Arabic usage was limited to speaking to their parents back home or with some Arabic-speaking acquaintances. The mean percentage of their estimate Arabic daily usage was less than $25.0 \%$. Participants rated themselves at least 5 on a 7-point Likert scale regarding their English competence with a mean score of 5.6. (See Table 1 below for a summary of pertinent information about the participants)

Table 4: Participants' Information. $\mathrm{Y}=$ years $\mathrm{M}=$ months

\begin{tabular}{lllllll}
\hline Group & Gender & $\begin{array}{l}\text { Mean } \\
\text { Age (Y) }\end{array}$ & $\begin{array}{l}\text { Mean } \\
\text { AoL (Y) }\end{array}$ & $\begin{array}{l}\text { Mean } \\
\text { LoR (M) }\end{array}$ & $\begin{array}{c}\text { Mean \% } \\
\text { L2 Use }\end{array}$ & $\begin{array}{c}\text { Mean L2 } \\
\text { self-rating }\end{array}$ \\
\hline Intermediate & 10 Males & 21.78 & 20.89 & 10.7 & 26.3 & 3.04 \\
& 13 Females & & & & & \\
\hline Advanced & $\begin{array}{l}\text { 14 Males } \\
\text { 9 Females }\end{array}$ & 21.73 & 19.96 & 21.34 & 75.43 & 5.6 \\
& & & & & \\
\hline
\end{tabular}

Participants from both groups were born and raised in Saudi Arabia and went through the Saudi school system until after high school. After finishing high school, they moved to the United States because they have been either awarded scholarships to continue their bachelor degrees or were here to learn English and go back to their country. Although all participants took very basic English classes as a mandatory foreign language requirement in their primary education, they reported that they were not able to neither understand nor communicate in English when they first arrived to the United 
States. It is important to mention that the L2 input in these classes in Saudi Arabic was non-native and was highly mixed with Arabic most of the time.

\subsection{Stimulus Materials:}

The stimulus materials are presented in Appendix B. The purpose of this thesis is to investigate the production of different English initial clusters with two members with different sonority ranges; therefore, it was decided to include 17 English double onsets. Each target cluster was tested in three monosyllabic words, in the target words the clusters were followed by three different vowels /æ, i, u/ (e.g., for the cluster /f1/ the target words were "flag, flee, flu"), yielding a total of 51 target words. Each target word, then, was placed in the middle of a short sentence resulting in 51 experimental sentences (Appendix B). These three different vowels were used specifically because they are very similar to the Arabic vowels. The sound preceding the target word was either the voiced or voiceless alveolar stop /t/ or /d/ respectively. Examples 1-3 below show some experimental sentences used in this study:

1. She said please to him

2. The flight crew came late

\section{Kim visited France last year}

The reason for choosing alveolar stops to precede the clusters was because these two stops are found in the Arabic phonetic inventory. Controlling the phonetic environment preceding and following the target cluster helps reduce any unwanted effects of other sounds. Also, this was partially motivated by the fact that alveolar stops + target clusters (e.g., /t/ + /fl/) do not make possible cluster in English or Arabic (i.e., it is impossible to find a word starting with two stops, a stop + fricative in neither language). 
In addition to the 51 experimental sentences, nine filler sentences were used making up a total of 60 sentences. The 60 sentences were then randomized.

\subsection{Procedure:}

After the identification of potential participants in the two groups based on their linguistic competence and language history, scheduling appointments took place. Those who qualify to participate in the study were scheduled to come to a quiet study room at Florida International University for 30 minutes. The meeting appointments were scheduled at different times to ensure that participants do not meet each other.

At the beginning of the meeting, the researcher explained the nature of the experiment in English. Participants were told that the study involves reading sentences, silently, from a computer screen and when the screen turns blank they would repeat what they saw out loud and that their speech would be audio recorded for further acoustic analysis. However, this method of elicitation was difficult for most of the participants given their level of proficiency in English and the difficulty of remembering the whole sentence, which resulted in missing the target words occasionally. Therefore, it was decided to use a self-paced reading task where participants would read sentences directly from a computer screen. It is important to mention that the elicitation of sentences by reading serves the primary purpose of this study since it provides the required data to evaluate the productions of the clusters. In order to unify the elicitation method, it was decided that recordings from some participants who were able to perform the experiment in its original shape would be excluded from this study. Participants were, then, given a chance to ask any questions they might have, then read and understand the consent form then sign it. 
After signing the consent form, participants sat at a desk facing a computer screen with a Sony digital audio recorder placed at a distance of about $15 \mathrm{~cm}$ from their mouth. Participants were instructed to speak at a natural pace, neither too quickly nor too slowly. They were told to speak clearly and normally. Three practice sentences were shown before starting the experiment in order to familiarize the participants to the process. Sentences were appeared on the screen one sentence at a time in a random order. The time between slides was 4 -second intervals. The total recording time was approximately 7 minutes for each of the 46 participants.

\subsection{Acoustical Measurements:}

The recordings obtained from the participants were then converted to MP3 files and opened using the speech analyzer PRAAT for temporal and spectral qualities. The participants' productions of target clusters were analyzed in order to detect any cluster treatment. In the event where participants modified clusters by inserting a vowel, the formants of the inserted vowel was clearly identified on the spectrogram in the expected positions. Once an inserted vowel was identified, its duration was measured, F1 and F2 values were obtained and the nature of the vowel was determined in relation to its position to the target clusters (i.e., before the cluster or after the cluster).

\subsection{Methods of Analysis:}

In analyzing the data of this study, a distinction was made between $\#_{\mathrm{s}} \mathrm{C}$ clusters and non $\mathrm{H}_{\mathrm{s}} \mathrm{C}$ clusters. The reasoning for the separation will be addressed in the next chapter. For now the focus will be on the approaches of analyses. The framework selected for organizing and analyzing the data was markedness based on sonority. However, there was another approach that was also explored here, namely the input 
frequency. Most of the studies on the acquisition of consonant clusters considered sonority to be the primary variable; however, as reported in the previous chapter, there seem to be a growing interest in exploring the effect of input frequency. In fact, some studies have reported that input frequency may provide a better explanation for their data (e.g., Cardoso, John and French, 2009). Details on how each of these two approaches was be employed in this study are provided in the following:

\subsubsection{Markedness Based Analysis:}

For markedness analysis the target clusters were grouped according to their sonority distance between $\mathrm{C} 1$ and $\mathrm{C} 2$ (i.e., the number of sonority steps between $\mathrm{C} 1$ and $\mathrm{C} 2$ ). Baring in mind the distinction between $\mathrm{As}_{\mathrm{s}} \mathrm{C}$ clusters and non $\mathrm{AsC}_{\mathrm{s}}$ clusters, the grouping of clusters according to sonority distance yielded 4 groups for each $\# \mathrm{sC}$ clusters and non $\mathrm{H}_{\mathrm{s}} \mathrm{C}$ clusters. Tables $5 . \mathrm{a}$ and $\mathrm{b}$ below show the expected hierarchy based on Markedness.

Table 5.a: Non \#sC Clusters Based on Sonority Distance

\begin{tabular}{c|c}
\hline $\begin{array}{c}\text { Sonority } \\
\text { Distance } \\
\text { C2 - C1 }\end{array}$ & Target words \\
\hline $\mathbf{6}$ & priest, prank, proof, cream, crash, crew (/pr, kr/) \\
\hline $\mathbf{5}$ & please, plan, *Pluto, clean, class, clue, breeze, brand, bruise, green, grass, \\
group (/pl, kl, br, gr/)
\end{tabular}


Table 5.b. \#sC Clusters Based on Sonority Distance

\begin{tabular}{c|c}
\hline $\begin{array}{c}\text { Sonority } \\
\text { Distance } \\
\mathbf{C 2}-\mathbf{C 1}\end{array}$ & Target words \\
\hline $\mathbf{5}$ & sweep, swam, swoon $(/ \mathrm{sw} /)$ \\
\hline $\mathbf{3}$ & sleep, slap, sloop $(/ \mathrm{sl} /)$ \\
\hline $\mathbf{2}$ & smear, smash, smooth, sneeze, snap, snoop $(/ \mathrm{sm}, \mathrm{sn} /)$ \\
\hline $\mathbf{- 2}$ & speak, spam, spoon, steal, stamp, stool, ski, scan, school $(/ \mathrm{st}, \mathrm{sk}, \mathrm{sp} /)$ \\
\hline
\end{tabular}

In the tables above, for instance, target words starting with /pr/, were ranked to have sonority distance of 6 steps between $\mathrm{C} 1$ and $\mathrm{C} 2$. This is because the first member is a voiceless stop /p/ with a sonority index of 1 on Hogg and McCully's scale (table 1) and the $/ \mathrm{r} /$ has a sonority index of 7 , which means that the difference is 6 points or sonority steps between $\mathrm{C} 1$ and $\mathrm{C} 2$. Therefore, for the markedness based on sonority approach, the hypothetical hierarchy will be as follows: (where " $\rightarrow$ " means acquired before).

\section{Non \#sC clusters: Son.D $6 \rightarrow$ Son.D $5 \rightarrow$ Son.D $4 \rightarrow$ Son.D 3 \#sC clusters: Son.D $5 \rightarrow$ Son.D $3 \rightarrow$ Son.D $2 \rightarrow$ Son.D -2}

\subsubsection{Frequency Based Analysis:}

The current study consulted different English corpora in order to explore and create a possible developmental path according to the frequency of the input of the clusters. The exploration of input frequency may help decide whether input frequency could offer a better explanation than markedness (sonority) for the results of this study. Therefore, it was decided that frequencies for both cluster types and tokens would be obtained using different corpora. 
Type frequency refers to the number of instances where a given cluster type such as /st/ or /pr/ has appeared in a given corpus regardless or the actual words in which they occurred. Token frequency refers to the number of instances in which a specific target word appeared in a given corpus, such as the word "sleep" or "flee".

In order to account for the frequency of tokens, the Brown corpus (Kucera \& Francis, 1967) was used. Brown corpus is based on 190,000 words of English appearing in conversation. CELEX (Baayen et al., 1993) was also used to account for the frequency of types. CELEX is an online searchable database for lexicon based on written and spoken input for different languages including English.

So, for example in Brown's corpus there were (492) instances of the word school, this is considered as the token frequency, whereas the cluster type /sk/ has appeared in (559) instances in CELEX database. Therefore, there are two expected hypothetical orders; one according to types frequency and the other is according to tokens frequency. These two hierarchies are represented in the following tables for both $\#_{\mathrm{sC}}$ and non $\mathrm{AsC}_{\mathrm{s}}$ clusters.

Table 6a: Input frequency for $\mathrm{AsC}_{\mathrm{s}}$ clusters ("“” means more frequent)

\begin{tabular}{l|l}
\hline & Prediction \\
\hline Type & st $>$ sp $>$ sk $>$ sl $>$ sw $>$ sn $>$ sm \\
\hline Token & sk $>$ sp $>$ sl $>$ sm $>$ st $>$ sw $>$ sn \\
\hline
\end{tabular}


Table 6b: Input Frequency for non \#sC clusters (">> means more frequent)

\begin{tabular}{l|l}
\hline & Prediction \\
\hline Type & $\mathrm{pr}>\mathrm{kr}>\mathrm{br}>\mathrm{gr}>\mathrm{fl}>\mathrm{fr}>\mathrm{kl}>\mathrm{pl}>\mathrm{bl}>\mathrm{gl}$ \\
\hline Token & $\mathrm{gr}>\mathrm{fr}>\mathrm{kl}>\mathrm{pl}>\mathrm{bl}>\mathrm{gl}>\mathrm{kr}>\mathrm{pr}>\mathrm{fl}>\mathrm{br}$ \\
\hline
\end{tabular}




\section{CHAPTER 4: Results and Discussion}

\subsection{Introduction:}

In this thesis, a total of 2346 tokens were analyzed from the recordings ( 17 initial clusters $\times 3$ target items x 46 participants). Initial results indicated that participants in the advanced group produced all of the clusters more correctly $(\mathrm{M}=87.47 \%, \mathrm{SD}=10.24 \%)$ than did those in the intermediate group $(\mathrm{M}=64.35 \%, \mathrm{SD}=12.53) t(44)=-2.01(\mathrm{p}<.001)$. The significant mean difference of $(23.12 \%)$ between the two participant groups clearly showed that participants in the advanced group had a learning time advantage over participants in the intermediate group, which was something this study predicted.

Since this study initially intended not to deal with individual clusters but rather with cluster groups based on their sonority profiles, results reported in the following sections will address clusters as groups, unless specified otherwise. The direct consideration of individual clusters will, however, be needed when looking at frequency effects. Also, as briefly mentioned in the previous chapter, this study makes a distinction between \#sC clusters and Non \#sC clusters sonority distance (Son.D) groups. Such separation in reporting the results is justified by two reasons: one is because of the different analyses of $\#_{\mathrm{s} C}$ clusters found in the literature and two because of the unique behavior of the \#sC clusters in this study. The latter will be dealt with when reporting the results below. For now, however, a brief discussion of the major analyses of $\#_{\mathrm{s}} \mathrm{C}$ clusters is needed.

In the literature, there are unsettled debates about whether or not \#sC clusters should be analyzed with non \#sC clusters. The views about this topic are divergent; 
however, there have been four major analyses proposed for analyzing \#sC clusters (cf. Goad, 2011; Cardoso, 2008; Yavaş, 2013).

Many scholars proposed that the $\mathrm{AsC}_{\mathrm{S}}$ clusters should not be considered different from other non $\#_{\mathrm{sC}}$ clusters (see figure 5.1.a). According to this analysis, there is no need to make a distinction between the two cluster types with the assumption that all clusters behave in the same fashion (e.g., Ohala, 1999; Cardoso, 2008).

Other scholars, however, have suggested that $/ \mathrm{s}+\mathrm{Stop} /$ clusters are different from other cluster types and, subsequently, they should be regarded as parts of complex segments (see Figure 5.1.b) (e.g., Selkirk, 1982; Yildiz, 2005). This analysis only includes the /s/ + Stop/ clusters (e.g., /st, sp, sk/) because of their "falling" sonority and, therefore, their violation of the SSP. Given that other \#sC clusters such as $/ \mathrm{s}+$ nasal/ and /s + lateral/ have "rising" sonority, it is assumed that they behave like non \#sC clusters.

A third analysis proposed that all \#sC clusters should be analyzed independently. According to the analysis, all \#sC clusters are considered to be different from other complex clusters; they proposed that $\#_{\mathrm{s}} \mathrm{C}$ clusters are not classified as "true clusters" but rather "adjuncts" (see Figure 5.1.c) placed outside the cluster constituents (e.g., Giegerich 1992; Kenstowicz, 1994; Barlow, 2001; Yavaş \& Someillan, 2005; Yavaş \& Barlow, 2006; Yavaş 2013).

The fourth analysis proposed that rather than treating \#sC cluster as "adjuncts", they should be treated as an extra-syllabic (see Figure 5.1.d) or "appendix ". (e.g., Goad \& Rose, 2004; Goad, 2011). This study only assumes that all \#sC clusters are different from non \#sC clusters and should be analyzed separately. 
Figure 5.1. (a, b, c, d): The representations of \#sC clusters (from Cardoso 2008)

a) Branching Onset

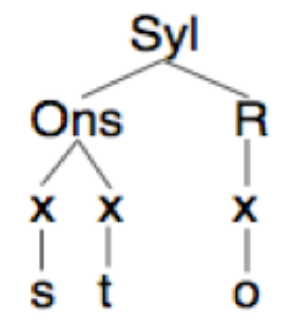

c) Adjunct

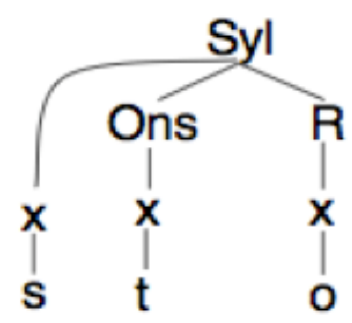

b) Complex Onset

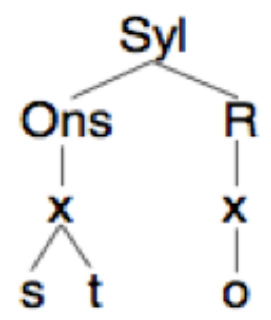

d) Extrasyllabic

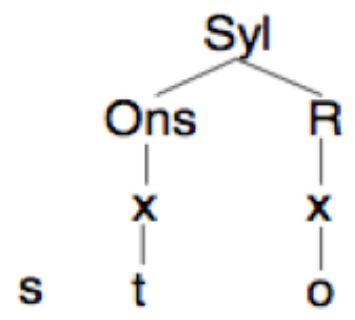

In addition to the different analyses of the $\mathrm{ASC}$ clusters, the different behavior observed between the $\#_{\mathrm{sC}}$ clusters and non $\mathrm{H}_{\mathrm{sC}}$ clusters in this study required the separation in reporting the results as will be shown below.

\subsection{Results based on Markedness by Sonority:}

\subsubsection{Results from \#sC clusters groups:}

The \#sC clusters tested in this study were grouped according to the sonority distance between $\mathrm{C} 1$ and $\mathrm{C} 2$, yielding four sonority distance groups: $/ \mathrm{s} /+$ glide $=$ Sonority Distance 5, /s/ + lateral $=$ Sonority Distance 3, /s/ + Nasal = Sonority Distance 2 and $/ \mathrm{s} /+$ Stop $=$ Sonority Distance -2 . In comparing the overall performance of both participant groups in $\mathrm{A}_{\mathrm{s}} \mathrm{C}$ clusters, results showed that there was a significant effect of proficiency level; participants in the intermediate group produced $64.2 \%$ of all initial \#sC clusters correctly, whereas, participants in the advanced group had a 92.7\% accuracy rate. 
The significant difference of approximately $29 \%$ of correct production suggested that the average 11-month advantage that advanced group had over the intermediate group may be enough for them to reach a complete acquisition stage (advanced participants produced each of the $\mathrm{As}_{\mathrm{s}}$ clusters with a mean of correct production always higher than $88 \%$ ). Further, this finding suggested that experience is very crucial to the L2 phonological development.

In order to further explore the percentages of correct production for each sonority distance group by participant groups, an independent samples t-test was performed. Results obtained from this test showed a highly significant difference in the percentages of correct production for all of the sonority distance groups between the two participant groups. The results are displayed in Table 7 below.

Table 7: Independent Samples t-test for percentage of correct production for $\#_{\mathrm{s} C}$ clusters by groups

\begin{tabular}{|c|c|c|c|c|c|c|}
\hline \multirow[b]{2}{*}{ Cluster } & \multicolumn{2}{|c|}{$\begin{array}{l}\text { Intermediate } \\
(\mathrm{N}=23)\end{array}$} & \multicolumn{2}{|c|}{$\begin{array}{c}\text { Advanced } \\
(\mathrm{N}=23)\end{array}$} & \multirow[b]{2}{*}{$t$} & \multirow[b]{2}{*}{$p$} \\
\hline & Mean & $\begin{array}{c}\text { Standard } \\
\text { Deviation } \\
\end{array}$ & Mean & $\begin{array}{c}\text { Standard } \\
\text { Deviation } \\
\end{array}$ & & \\
\hline Son.D 5 & 82.60 & 26.34 & 98.55 & 6.95 & -2.80 & .005 \\
\hline Son.D 3 & 73.91 & 30.07 & 97.10 & 9.60 & -3.52 & .001 \\
\hline Son.D 2 & 64.52 & 23.11 & 91.91 & 12.26 & -5.02 & .000 \\
\hline Son.D -2 & 64.91 & 28.18 & 87.56 & 12.54 & -3.52 & .001 \\
\hline
\end{tabular}

Results presented in the table above provided support for two of the OPM predictions: The first is about the expected hierarchy among clusters and the second is 
regarding the influence of markedness throughout the L2 phonological development. These two predictions will be discussed in turn.

The clusters included in each of the sonority groups above were in markedness relationships. In other words, we expect to see the following direction in the acquisition (where " $\rightarrow$ " indicates direction from less marked to more marked).

$$
/ \mathrm{s}+\text { Glide } / \rightarrow / \mathrm{s}+\text { Lateral } / \rightarrow / \mathrm{s}+\text { Nasal } / \rightarrow / \mathrm{s}+\text { Stop } /
$$

The direction illustrated above is a result of the arrangement of clusters according to their sonority distance between the $\mathrm{C} 1$ and $\mathrm{C} 2$. The distance is greater for /s + glide/ (5 sonority steps) than it is for $/ \mathrm{s}+$ lateral/ (3 sonority steps), which makes $/ \mathrm{s}+$ glide/ more natural and therefore less marked.

According to the OPM predictions for marked structures, we expect to see a hierarchy in the acquisition of the onsets with the likelihood of higher rate of correct production for less marked onsets and the likelihood of less accuracy for more marked onsets. By comparing the percentages of correct production for each sonority group to the expected hierarchy, it was revealed that the percentages of the correct productions corresponded to the expected hierarchy in both participant groups,

\section{Son.D $5 \rightarrow$ Son.D $3 \rightarrow$ Son.D $2 \rightarrow$ Son.D -2.}

Figure 6.1.a below clearly depicts the hierarchal pattern among the sonority distance groups based on their relative degrees of markedness. 
Figure 6.1.a The percentages of Correct Production for $\mathrm{AsC}_{\mathrm{S}}$ clusters

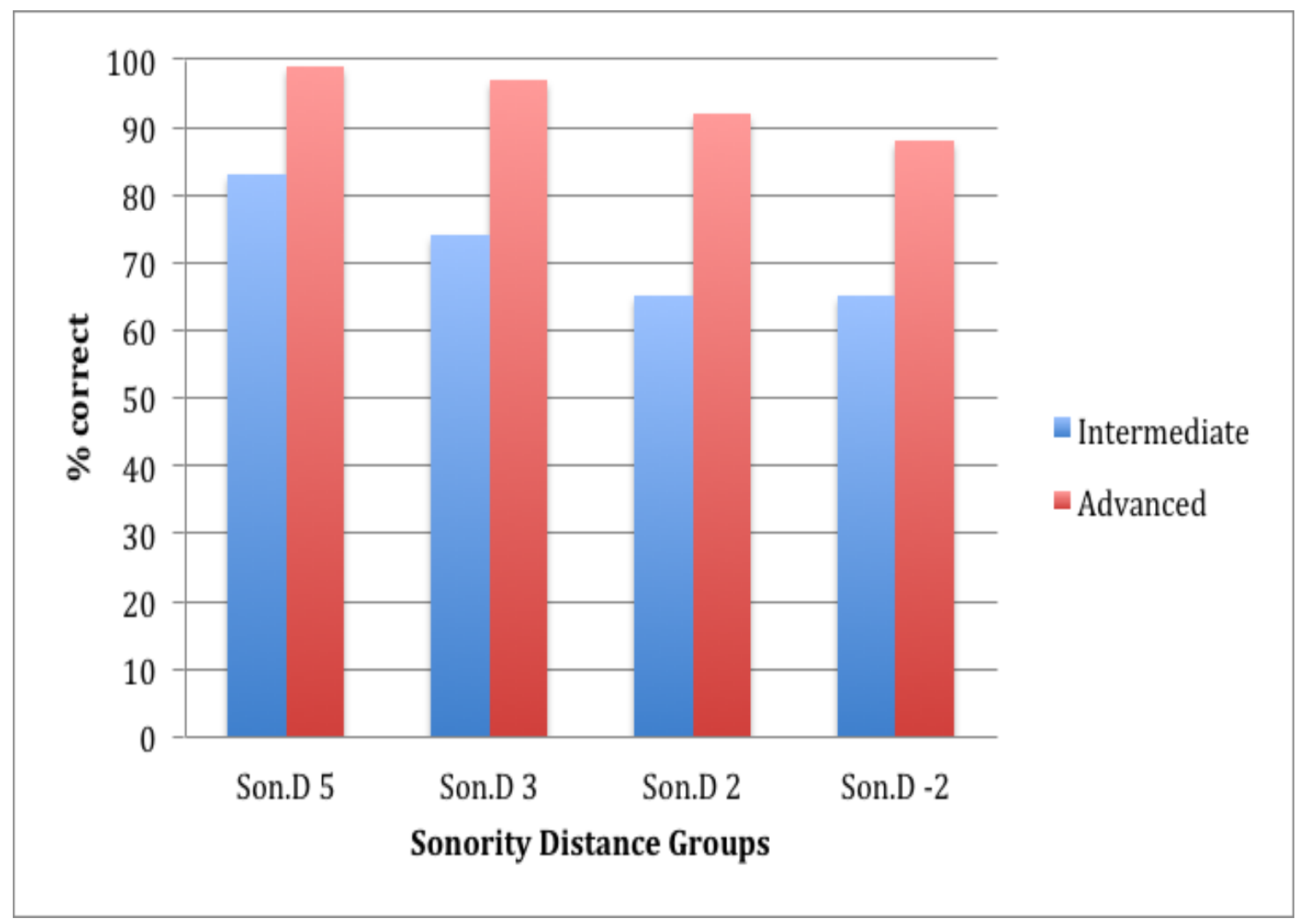

The figure 6.1.a illustrated that the direction of increase in percentages of correct production was consistent with sonority predictions for both groups, because as we moved from the more marked onset group (sonority distance -2) with the lowest percentage of correct production to less marked ones the percentages of correct production got higher. In other words, both participant groups were performing better in clusters with greater sonority distance between $\mathrm{C} 1$ and $\mathrm{C} 2$ (i.e., less marked) than other clusters with smaller sonority distances between $\mathrm{C} 1$ and $\mathrm{C} 2$ (i.e., more marked). Further, as the sonority distance between $\mathrm{C} 1$ and $\mathrm{C} 2$ got smaller the error rate increased resulting in Sonority distance -2 to be the cluster with lowest accuracy rate. 
Figure 6.1.b Box plot for the percentages of correct production for $\# \mathrm{sC}$ clusters by groups

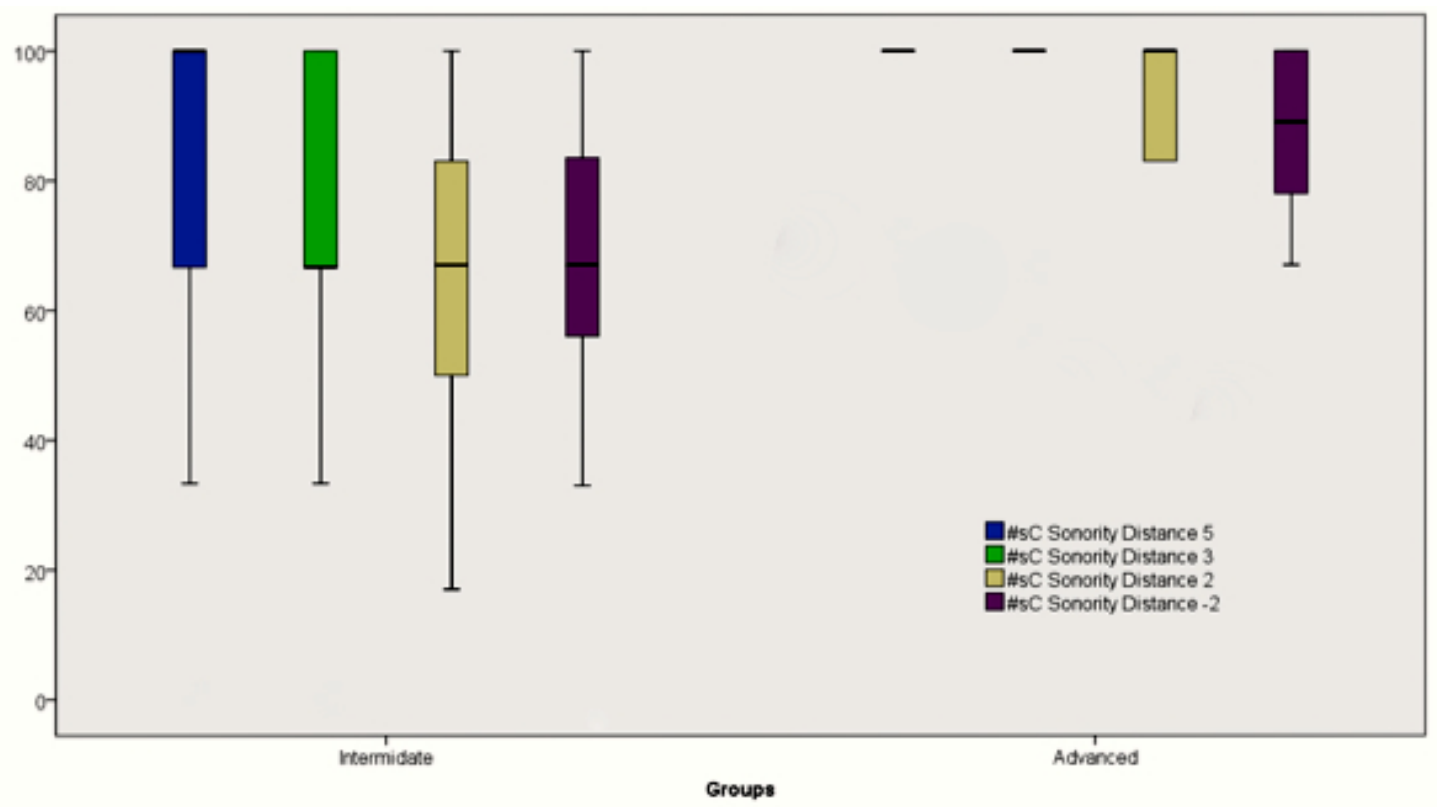

Figure 6.2.b. showed that the performance between intermediate and advanced was very different. In the advanced group, the ranges for sonority distances 5 and 3 were very small because participants produced these clusters almost with $100 \%$ accuracy. For the sonority distances 2 and -2 , advanced participants showed variations in performance but the median for sonority distance 2 is higher than the median in sonority distance -2 . Overall, the advanced participants performed higher than the intermediate participants. By examining the performance for the intermediate participants (on the left side of the box plot), it was revealed that intermediate participants produced clusters in the sonority distances 5 and 3 with higher ranges than sonority distances 2 and -2 , which suggests higher accuracy in sonority distances of 5 and 3 . The performance in sonority distances 2 and -2 by intermediate participants was relatively similar. The comparatively tall box plots for the intermediate participants (four plots on the left) showed consistency with the 
prediction made by the OPM, which states that markedness effect is stronger in intermediate stages.

The OPM predicts that in the intermediate stages of language learning the influence of markedness should be more apparent. Specifically, the influence of markedness diminishes over time. Since, markedness has a greater influence on the intermediate stages more than on the advanced stages, the expected pattern would be significantly less accuracy among intermediate participants. This prediction was also supported by results from the $\#_{\mathrm{SC}}$ cluster sonority groups; the higher accuracy levels of the advanced group suggested that the markedness effect has greatly diminished and the onsets have reached complete acquisition stage (no sonority distance group was below $88 \%$ of correct production). On the other hand, the stronger influence of markedness was evident in the results from the intermediate group especially in more marked clusters. The relatively lower percentages for sonority distance 2 and sonority distance-2 (65\%) in the intermediate group suggest a strong influence of markedness. Although it does not change the fact that the OPM prediction was supported here, the fact that sonority distance 2 and sonority distance -2 were produced at the same level of accuracy may raise questions as to whether participants were actually sensitive to the violation of the SSP or to the number of the sonority steps. Both sonority distances 2 and -2 are within 2 steps difference on the sonority scale but in the opposite directions. Similar behavior was also observed in L1 studies (e.g., Gierut, 1999; Yavaş \& Someillan, 2005; Yavaş, Ben-David, Gerrits, Kristoffersen \& Simonsen, 2008). Gierut (1999) suggested that participants may be treating all sonority distances of 2 as a "natural class", regardless of the direction in which sonority heading, either "rising" as in /s+nasal/ or "falling" as in /s+stop/. 
According to Yavaş et al. (2008) and Yavaş (2013), the similar behavior between $/ \mathrm{s}+$ nasal/ and /s+stop/ may not be because of sonority distance but rather because the second consonant is [-continuant]. Since in both nasals and stops the airflow is obstructed, this maybe motivated the creation of an independent group sharing the [continuant] feature (Yavaş et al., 2008). The data in this study did not provide enough evidence to support neither.

Because of the high percentages of correct productions for $\mathrm{AsC}_{\mathrm{S}}$ clusters in the advanced group, no statistical test in comparing the percentages was attempted. A paired samples t-test, however, was performed on results from the intermediate group. (see Table 8).

Table 8: Paired samples t-test results for percentages of correct production for \#sC clusters sonority distances by intermediate group

\begin{tabular}{|c|c|c|c|c|c|}
\hline \multirow[b]{2}{*}{ Pair } & \multicolumn{2}{|c|}{$\begin{array}{c}\text { Intermediate } \\
(\mathrm{N}=23)\end{array}$} & \multirow[b]{2}{*}{$t$} & \multirow[b]{2}{*}{$d f$. } & \multirow[b]{2}{*}{$\begin{array}{l}\text { Sig. }(2- \\
\text { tailed) }\end{array}$} \\
\hline & $\mathrm{M}$ & $\begin{array}{c}\text { Standard } \\
\text { Deviation }\end{array}$ & & & \\
\hline Son.D5-Son.D3 & 8.69 & 33.66 & 1.23 & 22 & .228 \\
\hline Son.D3-Son.D2 & 9.39 & 20.03 & 2.24 & 22 & $.035^{*}$ \\
\hline Son.D2-Son.D-2 & -0.39 & 26.60 & -0.07 & 22 & .944 \\
\hline
\end{tabular}

Results revealed that both sonority distances 2 and -2 were significantly lower than both sonority distance 5 and sonority distance 3 . There was no significant observed between sonority distances 5 and 3 nor between sonority distances 2 and -2 . Considering the mean difference between the sonority distances 5 and 3 (8.69\%), although it was not very huge, it still supported the hypothesis. Further, sonority distance 5 was produced 
correctly at the $83 \%$ level, which marked the complete acquisition stage. In the case of sonority distance 3 , the percentage of correct production was $74 \%$; hence, it did not reach the acquisition criterion.

In summary, the OPM predicts that the degree of the markedness of a given onset has strong influence on the rate of correct production of that onset. Moreover, the OPM postulates that the influence of markedness is more evident in intermediate stages more than advanced ones. The findings listed above supported the OPM predictions. According to the OPM, L1 transfer is dominant in the initial stages of learning an L2 with no influence of markedness; however, as learning develops and reaches intermediate stages, markedness influence increases and then decreases in advanced stages. Although, the initial stage of language learning was not tested here, the presence of the two other predicted patterns in the different learning stages (i.e., the increase and the decrease of markedness influence) suggested that an L1 transfer stage must have been evident at earlier stages. The OPM predictions suggested that participants from both groups would acquire less marked onsets before more marked ones, which was the case for \#sC clusters in this study. The percentages of correct productions observed for the sonority distance groups also suggested that less marked $\mathrm{AsC}_{\mathrm{S}}$ clusters would likely be fully acquired before more marked ones (i.e., Son.D $5 \rightarrow$ Son.D $3 \rightarrow$ Son.D $2 \rightarrow$ Son.D -2 ). In fact, other studies have shown similar results, in Eckman (1991) and Eckman \& Iverson (1993), for example, it has been reported that marked onsets were typically fully acquired after less marked ones. Table 9 below summarizes the predicted pattern by the OPM and the observed pattern based on the results divided by participant groups: 
Table 9: OPM predicted pattern for \#sC clusters and groups performance where " $>$ " Indicates higher accuracy.

\begin{tabular}{|c|c|}
\hline Predicted Pattern & /sw/ Son.D $5>$ /sl/ Son.D $3>$ /sN/ Son.D $2>$ /sT/ Son.D -2 \\
\hline Intermediate & $/ \mathrm{sw} /$ Son.D $5>/ \mathrm{sl} /$ Son.D $3>/ \mathrm{sN} /$ Son.D $2=/ \mathrm{sT} /$ Son.D -2 \\
\hline Advanced & $/ \mathrm{sw} /$ Son.D $5>/ \mathrm{sl} /$ Son.D $3>/ \mathrm{sN} /$ Son.D $2>/ \mathrm{sT} /$ Son.D -2 \\
\hline
\end{tabular}

\subsubsection{Results from non \#sC clusters:}

Although results from $\# \mathrm{sC}$ clusters supported the predictions about the influence of markedness relationships based on sonority on the correct production of clusters, it was not quite obvious in the case of non $\# \mathrm{sC}$ clusters. The criterion used in grouping the \#CC (non \#sC) clusters here was the same one used for \#sC clusters, where, the sonority distance (i.e., number of sonority steps according to the sonority scale) between $\mathrm{C} 1$ and C2 determined the sonority distance groups to which each cluster belongs. With that being said, we also had four sonority distance groups organized in accordance to their relative degree of markedness as follows:

Son.D $6(/ \mathrm{pr}, \mathrm{kr} /) \rightarrow$ Son.D $5(/ \mathrm{pl}, \mathrm{br}, \mathrm{kl}, \mathrm{gr}) \rightarrow$ Son.D 4 (bl, gl, fr) $\rightarrow$ Son.D 3 (fl) By comparing the percentages of correct productions for each sonority distance group between the two participant groups, it was revealed that the significant difference between the group's performance was also maintained across all non \#sC clusters.

Advanced participants produced the clusters significantly more correctly than intermediate participants. Results from the independent samples t-test, displayed in Table 10 shows the significance. 
Table 10. Independent Samples t-test for percentages of correct production for non $\#_{\mathrm{s}} \mathrm{C}$ clusters by groups

\begin{tabular}{lllllll}
\hline & $\begin{array}{l}\text { Intermediate } \\
(\mathrm{N}=23)\end{array}$ & $\begin{array}{l}\text { Advanced } \\
(\mathrm{N}=23)\end{array}$ & & \\
Cluster & Mean & $\begin{array}{l}\text { Standard } \\
\text { Deviation }\end{array}$ & Mean & $\begin{array}{l}\text { Standard } \\
\text { Deviation }\end{array}$ & $t$ & $p$ \\
\hline Son.D 6 & 73.18 & 24.48 & 94.92 & 7.84 & -4.05 & .000 \\
Son.D 5 & 51.44 & 21.85 & 77.17 & 17.44 & -4.41 & .000 \\
Son.D 4 & 62.80 & 24.52 & 84.05 & 17.67 & -3.37 & .002 \\
Son.D 3 & 72.46 & 29.56 & 94.20 & 16.36 & -3.08 & .004
\end{tabular}

Significance is at .05 level

As expected, the table showed that advanced group had significantly higher percentages of correct production across all sonority distance groups. The fact that three of the four sonority distance groups were produced with accuracy above $84 \%$ of correct production suggested that clusters contained within these groups have reached the complete acquisition stage. A discussion of the one sonority distance (i.e., Son.D 5) group that was less than $80 \%$ in the advanced group will be addressed later.

The intermediate group did not produce any of the sonority distance groups with more than $74 \%$ of correct production. Strikingly, by examining the percentages of correct production for each participant group, it was clear that the pattern observed was not consistent with the prediction. Both participant groups did not seem to fully follow the hierarchal pattern predicted by markedness based on sonority. Figure 7 below displays the pattern based on the percentage of correct production by sonority distance groups: 
Figure 6.2.a: The percentages of Correct Production for non $\# \mathrm{sC}$ clusters

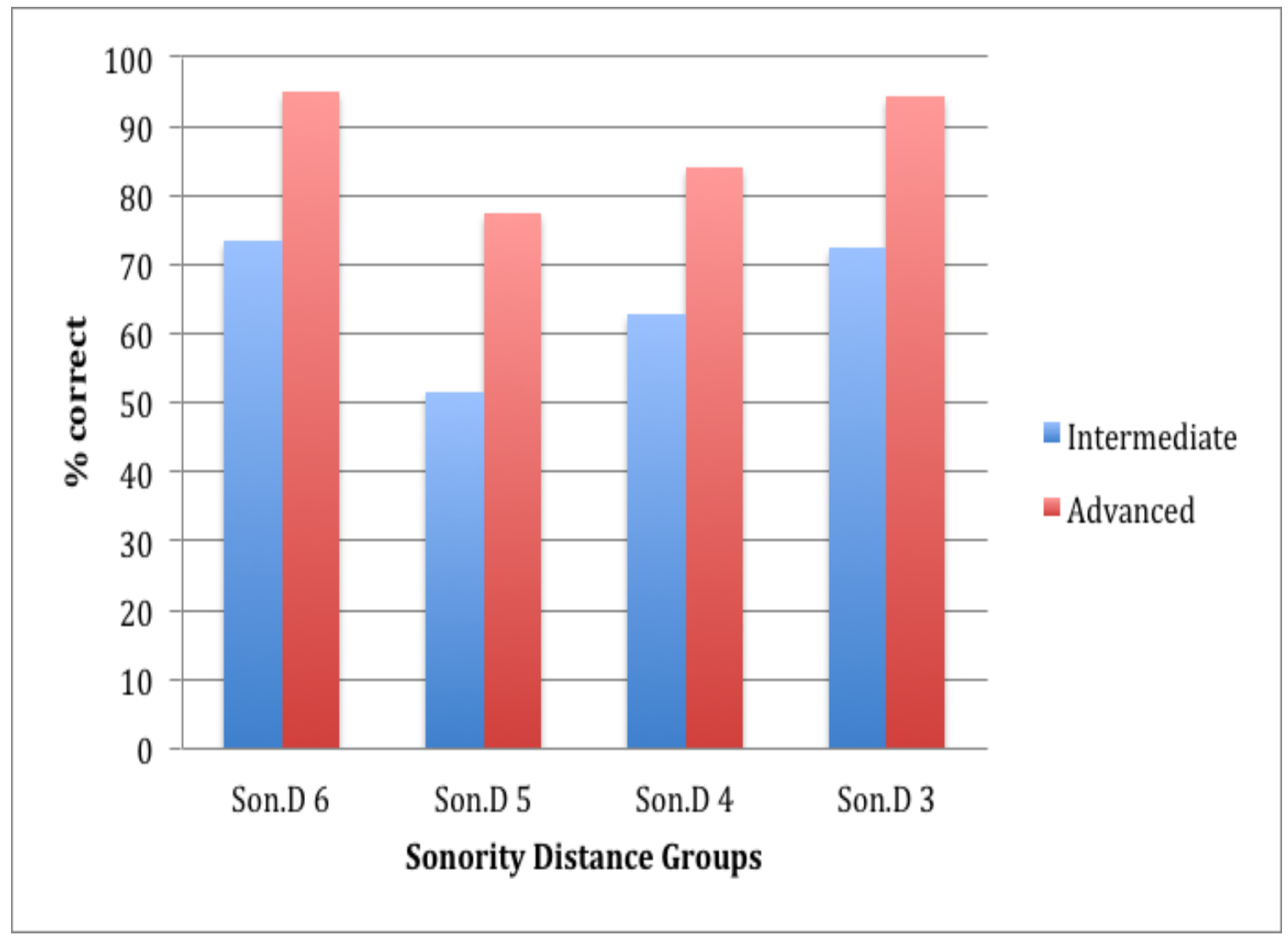

Overall, the advanced group produced the clusters with high frequency of correct production with no sonority distance group less than $84 \%$ except for one distance, namely Son.D 5 with 77\%. The intermediate group produced all of the clusters less accurately than advanced group with no sonority distance group over $73 \%$ of correct production. In fact, the intermediate group performed poorly on Son.D 5 and Son.D 4. Results from both participant groups showed that only two sonority distance groups corresponded to the expected hierarchy, namely Son.D 6 and Son.D 5, which yielded partial support for the markedness hypothesis. The relatively higher percentages of correct production for Son.D 4 and Son.D 3 posed a challenge for markedness predictions. 
Figure 6.2.b Box plot for the percentages of correct production for non $\# \mathrm{sC}$ clusters by groups

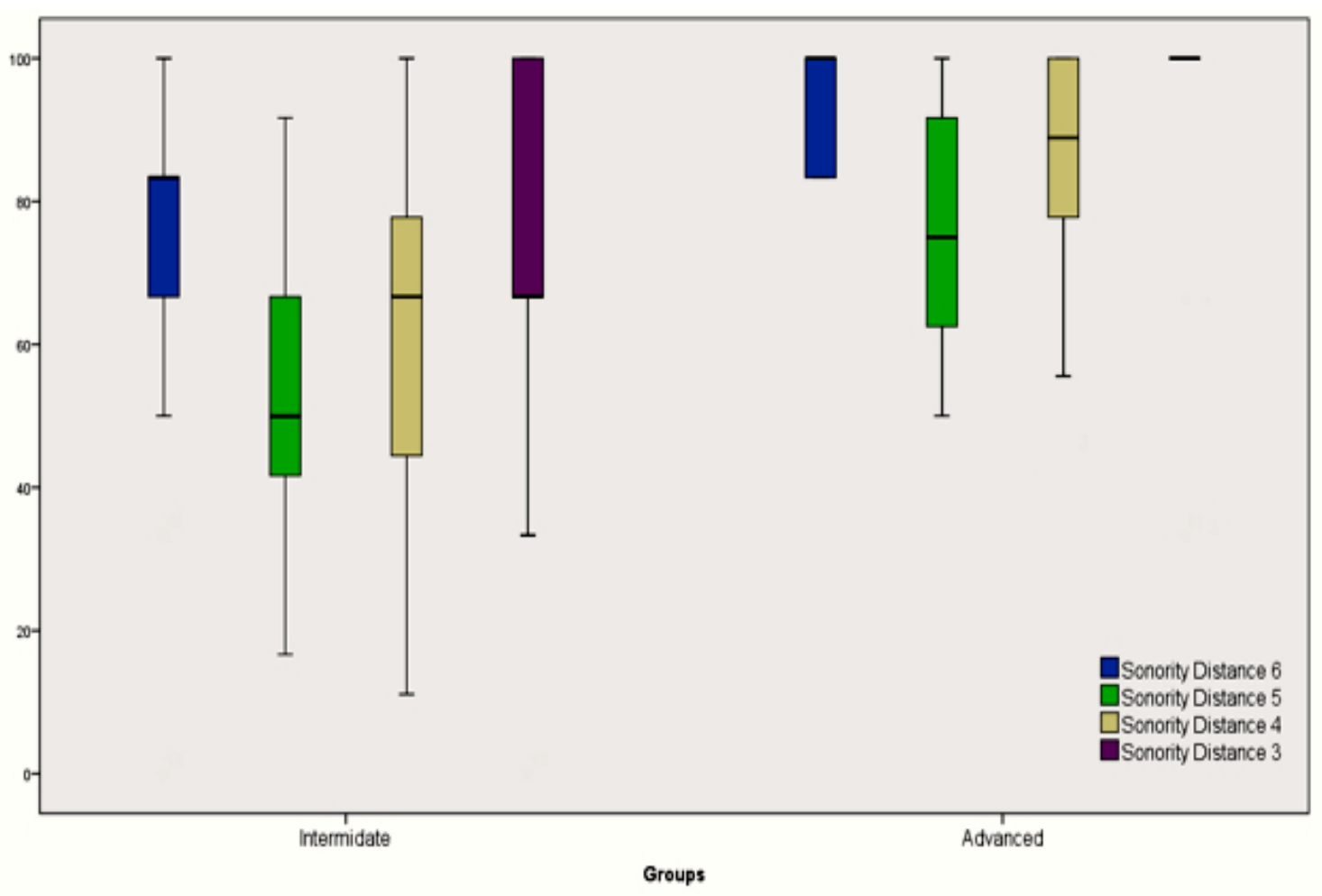

The box plot showed the performance (percentages of correct production) for advanced (right plots) and intermediate (left plots) participants in non \#sC clusters. Overall, the advanced group performed higher than the intermediate group. The relatively small range for sonority distance 6 and the small range for sonority distance 3 suggested that advanced participants were not very different in their performance in these two sonority distance groups. However, in sonority distances 5 and 4, the performance was different with more variation. On the other hand, the intermediate box plots were uneven in size; the percentages of correct production were not the same across the sonority groups. In sonority distance 6 , intermediate participants were relatively close to each other in performance. Sonority distances of 5 and 4 showed tall plots with lower medians, 
which suggested lower production accuracy. Medians for sonority distances 6 and 3, in the intermediate box plots were at the same level. However, the box plots for these two sonority distance groups showed very different distribution of performance, whereby intermediate participants produced sonority distance 3 with more variation than they did in sonority distance 6. Overall, the box plot showed that intermediate and advanced participants performed differently, and their performance did not conform with the performance predicted by the OPM.

A paired samples t-test was administered in order to explore whether the differences between the sonority distance groups in each participant group yielded any significance. Table 11 (advanced) and table 12 (intermediate) below display the results for each participant group.

Table 11: Paired samples t-test results for percentages of correct production for non \#sC clusters sonority distances by advanced group

\begin{tabular}{|c|c|c|c|c|c|}
\hline \multirow[b]{2}{*}{ Pairs } & \multicolumn{2}{|c|}{$\begin{array}{c}\text { Advanced } \\
(\mathrm{N}=23)\end{array}$} & \multirow[b]{2}{*}{$t$} & \multirow[b]{2}{*}{$d f$. } & \multirow[b]{2}{*}{$\begin{array}{l}\text { Sig. }(2- \\
\text { tailed) }\end{array}$} \\
\hline & $\begin{array}{c}\text { Mean } \\
\text { difference }\end{array}$ & $\begin{array}{c}\text { Standard } \\
\text { Deviation }\end{array}$ & & & \\
\hline Son.D6-Son.D5 & 17.75 & 15.13 & 5.62 & 22 & $.000^{*}$ \\
\hline Son.D5-Son.D4 & -6.88 & 11.84 & -2.78 & 22 & $.011 *$ \\
\hline Son.D4-Son.D3 & -10.14 & 27.19 & -1.78 & 22 & .087 \\
\hline
\end{tabular}

In the performance of advanced group there were two significant differences. The differences between Son.D 6 (95\%) and Son.D 5 (77\%) and between Son.D 5 (77\%) and Son.D $4(84 \%)$ were significant. Since the advanced group performed well in the other 
sonority distance groups except for (Son.D 5), the significance with Son.D 5 is predictable.

Intermediate participants, as can be seen in table 12 below, also showed similar pattern for the non $\mathrm{AsC}_{\mathrm{S}}$ sonority distance groups. The differences between Son.D 6 (73\%) and Son.D 5 (51\%) and between Son.D 5 (63\%) and Son.D 4 (84\%) were significant, but were not significant between Son.D 4 (63\%) and Son.D 3 (72\%). Both groups were consistent in the patterns, where they followed the prediction for the first two sonority groups (i.e., Son.D 6 and Son.D 5) and did the reverse for the remaining two (i.e., Son.D 3 and Son.D 4). In light of the OPM prediction, this only yielded partial support.

Table 12: Paired samples t-test results for percentages of correct production for non \#sC clusters sonority distances by intermediate group

\begin{tabular}{|c|c|c|c|c|c|}
\hline \multirow[b]{2}{*}{ Pairs } & \multicolumn{2}{|c|}{$\begin{array}{l}\text { Intermediate } \\
\qquad(\mathrm{N}=23)\end{array}$} & \multirow[b]{2}{*}{$t$} & \multirow[b]{2}{*}{$d f$} & \multirow[b]{2}{*}{$\begin{array}{l}\text { Sig. (2- } \\
\text { tailed) }\end{array}$} \\
\hline & $\begin{array}{c}\text { Mean } \\
\text { difference }\end{array}$ & Standard Deviation & & & \\
\hline Son.D6-Son.D5 & 21.73 & 20.05 & 5.19 & 22 & $.000^{*}$ \\
\hline Son.D5-Son.D4 & -11.35 & 18.53 & -2.93 & 22 & $.008^{*}$ \\
\hline Son.D4-Son.D3 & -9.66 & 30.94 & -1.49 & 22 & .148 \\
\hline
\end{tabular}

Thus far, results partly showed different behavior from those predicted by the OPM. Since, markedness based on sonority could not provide an explanation for such behavior (i.e., Son.D 4 and Son.D 3 with higher percentages of accuracy than Son.D 5). The fact that $\#_{\mathrm{s} C}$ clusters are more marked in nature than non $\#_{\mathrm{s} C}$ clusters would suggest that the influence of markedness would absolutely be more pronounced in more marked 
structures (in this case $\# \mathrm{~s} \mathrm{C}$ clusters). In fact, non $\# \mathrm{~s} C$ clusters are considered the least marked among all clusters, which suggests, that markedness may not fully explain the results. According to the OPM, in normal (i.e., unmarked) situations learners start with a completely developed L1 system with no other systems, during the initial stages the influence of the L1 is strong, which results in suppressing any possible influence of universals (such as markedness).

In the next stage, as the L2 starts to develop, universals start to surface, yet the L1 influence is more dominant. When the L2 is more developed the influence of the L1 and the universals start to decrease, but the influence of neither L1 nor universals can be identified separately. For us this means more production errors are expected in the intermediate group and more correct production in the advanced group. Both, the L1 transfer or universals, could account for the errors in both participant groups, however, there would be no clear pattern governing the $\mathrm{L} 1$ influence or universals on a given structure.

Therefore, considering that these clusters (i.e., non $\# \mathrm{~s} C$ clusters) are unmarked in nature, it would be more feasible to say that since the pattern observed among non \#sC clusters does not entirely follow the OPM predictions for marked phenomena, L1 transfer could better explain the errors. Transfer from the $\mathrm{L} 1$ is not restricted to certain structures and can occur at all levels. The influence of transfer, however, is stronger among intermediate learners than it is among advanced learners. Table 13, below, shows the predicted pattern by the OPM for non \# $\mathrm{sC}$ clusters and the observed performance by the participant groups: 
Table 13: OPM predicted pattern for non $\#_{\mathrm{s} C}$ clusters and groups performance where "> " indicates higher accuracy

\begin{tabular}{l|c}
\hline Predicted Pattern & Son.D 6 (/pr, kr/) > Son.D 5 (/pl, br, kl, gr ) > Son.D 4 (bl, gl, fr) $>$ \\
& Son.D 3 (fl) \\
\hline Intermediate & Son.D 6 (/pr, kr/) > Son.D 3 (fl) > Son.D 4 (bl, gl, fr) > \\
& Son.D 5 (/pl, br, kl, gr ) \\
\hline Advanced & Son.D 6 (/pr, kr/) $>$ Son.D 3 (fl) $>$ Son.D 4 (bl, gl, fr) $>$ \\
& Son.D 5 (/pl, br, , kl, gr $)$ \\
\hline
\end{tabular}

The findings from this section (i.e., Non \#sC Clusters) were consistent with previous findings obtained by Broselow (1992) from data from Arabic participants. Indeed, in Broselow's study, the conclusions made are of special interest to us. Broselow concluded that L1 transfer explained all errors from non $\mathrm{AsC}_{\mathrm{S}}$ clusters for both Iraqi and Egyptian participants. In Broselow's study, Egyptian participants employed epenthesis for non $\#_{\mathrm{sC}}$ clusters (e.g., play $\rightarrow$ pilay). However, in the case of \#sC clusters, Egyptian participants employed prothesis (e.g., speak $\rightarrow$ ispeak). Broselow concluded that since the behavior was different between the two cluster types, this suggested that errors in the unmarked clusters (non \# $\mathrm{sC}$ clusters) were due to L1 transfer and errors in the marked clusters (\#sC clusters) were due to universal principles (markedness). Further, she stated that since the errors pattern among Iraqi participants was always prothesis, it means that all errors by Iraqi participants were due to L1 transfer.

In the current study, Saudi participants performed similarly to the Iraqi participants in the sense that they always employed prothesis. However, although the 
explanation for the results from non \#sC clusters is L1 transfer, as it was in Broselow's, for the $\mathrm{AsC}_{\mathrm{SC}}$ clusters, the results from this study showed a pattern that is consistent with predictions made by universal principles (namely, markedness based on sonority) and therefore can only be explained by markedness. Although both this study and Broselow's study observed similar behaviors the interpretations are justifiably different.

\subsection{Results from Frequency Based Analysis:}

In addition to the classification of the clusters based on sonority, the input frequency for both cluster "types" and "tokens" were obtained from Brown Corpus (Kucera \& Francis, 1967) and CELEX (Baayen et al., 1993) as described in chapter 3. The hierarchy according to the frequency of cluster types and frequency of tokens were calculated, in order to explore whether frequency of the input may suggest better explanation for the dataset.

For the $\mathrm{AsC}_{\mathrm{s}}$ clusters, results showed that both the frequencies of types and tokens were irrelevant, as will be shown below (Table 14). Both of the participant groups performed differently from what was expected according to the frequency calculations. The participants rather followed what markedness has predicted.

The same observation holds true for the results from non $\mathrm{AsC}_{\mathrm{s}}$ clusters. The predicted pattern by both frequency of type and token could not account for the order of the clusters based on the percentages of correct production. Table 15 below shows the different predictions and outcomes by participant groups. 
Table 14: the distribution of \#sC clusters by input frequency

\begin{tabular}{l|l}
\hline Prediction Type & st $>\mathrm{sp}>\mathrm{sk}>\mathrm{sl}>\mathrm{sw}>\mathrm{sn}>\mathrm{sm}$ \\
\hline Intermediate & $\mathrm{sw}>\mathrm{sl}>\mathrm{sp}>\mathrm{sm}>\mathrm{sk}>\mathrm{sn}>\mathrm{st}$ \\
\hline Advanced & $\mathrm{sw}>\mathrm{sl}>\mathrm{sn}=\mathrm{st}>\mathrm{sm}>\mathrm{st}>\mathrm{sk}$ \\
\hline Prediction Token & $\mathrm{sk}>\mathrm{sp}>\mathrm{sl}>\mathrm{sm}>\mathrm{st}>\mathrm{sw}>\mathrm{sn}$ \\
\hline Intermediate & $\mathrm{sw}>\mathrm{sl}>\mathrm{sp}>\mathrm{sm}>\mathrm{sk}>\mathrm{sn}>\mathrm{st}$ \\
\hline Advanced & $\mathrm{sw}>\mathrm{sl}>\mathrm{sn}=\mathrm{st}>\mathrm{sm}>\mathrm{st}>\mathrm{sk}$ \\
\hline
\end{tabular}

Table 15: the distribution of non \#sC clusters by input frequency

\begin{tabular}{l|l}
\hline Prediction Type & $\mathrm{pr}>\mathrm{kr}>\mathrm{br}>\mathrm{gr}>\mathrm{fl}>\mathrm{fr}>\mathrm{kl}>\mathrm{pl}>\mathrm{bl}>\mathrm{gl}$ \\
\hline Intermediate & $\mathrm{kr}>\mathrm{fl}>\mathrm{fr}>\mathrm{br}>\mathrm{bl}>\mathrm{pr}>\mathrm{pl}>\mathrm{gl}>\mathrm{kl}>\mathrm{gr}$ \\
\hline Advanced & $\mathrm{kr}>\mathrm{pr}=\mathrm{fr}=\mathrm{fl}>\mathrm{br}>\mathrm{pl}>\mathrm{bl}>\mathrm{gl}>\mathrm{kl}>\mathrm{gr}$ \\
\hline Prediction Token & $\mathrm{gr}>\mathrm{fr}>\mathrm{kl}>\mathrm{pl}>\mathrm{bl}>\mathrm{gl}>\mathrm{kr}>\mathrm{pr}>\mathrm{fl}>\mathrm{br}$ \\
\hline Intermediate & $\mathrm{kr}>\mathrm{fl}>\mathrm{fr}>\mathrm{br}>\mathrm{bl}>\mathrm{pr}>\mathrm{pl}>\mathrm{gl}>\mathrm{kl}>\mathrm{gr}$ \\
\hline Advanced & $\mathrm{kr}>\mathrm{pr}=\mathrm{fr}=\mathrm{fl}>\mathrm{br}>\mathrm{pl}>\mathrm{bl}>\mathrm{gl}>\mathrm{kl}>\mathrm{gr}$ \\
\hline
\end{tabular}

\subsection{Vowel duration:}

Another focus of this study was the acoustic examination of the error pattern. By acoustically examining the error patterns among all clusters, it was found that participants restrictedly used vowel prothesis /i/ as a treatment method. The usage of a prothetic vowel could be attributed to transfer of a phonological rule from the L1. In Saudi Arabic, words may only start with one consonant as in /bab/ "door". In words where two consonants belonging to different syllables become adjacent, the insertion of a glottal 
stop followed by a prothetic vowel must take place as in the Saudi Arabic word /k.laab/ $\rightarrow$ / Pik.laab/ "dogs". In the data of this study prothesis was used 100\% with all errors in both \#sC clusters and non \#sC clusters. Broselow (1992) reported similar pattern among Iraqi and Egyptian speakers with the $\mathrm{AsC}_{\mathrm{S}}$ clusters.

What was of special interest to this study is the duration of the prothetic vowels. To my knowledge there are no studies reported in the literature for initial clusters looking at the duration of the prothetic vowel from a markedness standpoint. In fact, none of the studies reviewed here addressed the duration of the prothetic or epenthetic vowels at all. Thus, the prothetic vowels were measured in order to explore whether markedness of the onset has an influence on the duration of the inserted vowel. This study predicted that the duration of the prothetic vowel is expected to be longer in duration as markedness of the cluster increases. In other words, the smaller the sonority distance between $\mathrm{C} 1$ and $\mathrm{C} 2$ in a cluster, the longer the prothetic vowel will be and vice versa. In order to explore this topic the distinction between the $\# \mathrm{sC}$ clusters and non $\# \mathrm{sC}$ clusters needs to be maintained here as well.

\subsubsection{Vowel Duration for \#sC Clusters Groups}

In light of the markedness relationships among the $\mathrm{AsC}_{\mathrm{S}}$ sonority groups, it was predicted that clusters in Son.D 5 would have the shortest prothetic vowel in duration, followed by a longer prothetic vowel for Son.D 3, Son.D 2 respectively and finally Son.D -2 with the longest prothetic vowel in duration. Further, this hierarchical pattern for vowel duration was predicted to be observed across the participant groups.

By comparing the means for the duration of the prothetic vowels for each sonority distance group and for both participant groups, it was revealed that the prothetic vowel 
increased in duration as we moved from less marked sonority distance group to more marked ones. This hierarchical pattern conformed with the pattern found in the percentages of correct production. As can be seen in the Figure 8 below, the direction of the duration increase was consistent with the relative degree of markedness of the cluster group, the less marked the Son.D group was the shorter the vowel was and so on.

Figure 7.1.a: Duration of the prothetic vowel for $\mathrm{\#} \mathrm{s} \mathrm{C}$ cluster groups

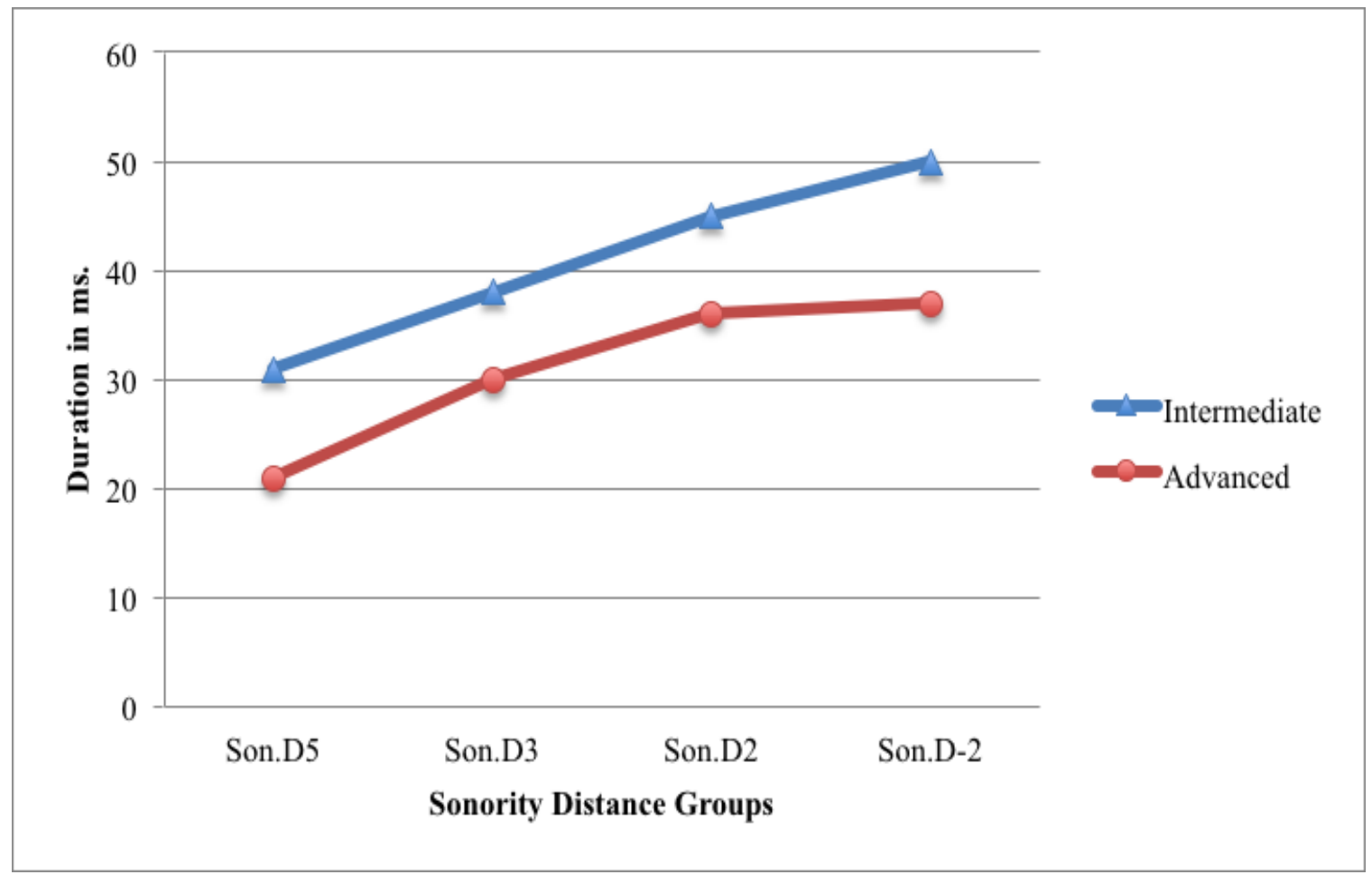

Expectedly, the figure above also showed that intermediate participant group tended to insert longer prothetic vowels than advanced participants. This further supported the OPM prediction regarding the strong influence of markedness in intermediate stages and the decrease of the influence in the advanced stages.

Since there were some gaps in the dataset, it was difficult to perform any statistical analysis, however, the previous findings suggested a strong tendency toward inserting a 
longer prothetic vowel in more marked onsets. A tendency like this is believed to be a result of a correlation between the relative degrees of markedness for clusters and the duration of prothetic vowels. Furthermore, the overall shorter prothetic vowels inserted by the advanced group may be taken as a further indication for the final stages of acquisition.

In summary, results from the duration of the prothetic vowels for $\#_{\mathrm{s}} \mathrm{C}$ sonority groups suggested that the more marked the onset is, the longer the prothetic vowel would be. Further, the earlier the learning stage is, the more likely to insert a longer prothetic vowel. Also, in later learning stages it is more likely that a prothetic vowel would be shorter. The results from this section supported the predictions made according to markedness principles.

\subsubsection{Vowel Duration For Non \#sC Clusters Groups}

The generalizations made in the previous section can be extended to include the prothetic vowels inserted in non \#sC cluster sonority groups. Although, the percentages of correct production for non $\mathrm{H}_{\mathrm{s}} \mathrm{C}$ clusters did not fully support the predictions about the markedness hierarchy among sonority distance groups, the duration of prothetic vowel partially did. Figure 9 below shows the duration of the prothetic vowel inserted by each participant group for each sonority group.

The observation made for the $\mathrm{AsC}_{\mathrm{s}}$ cluster can be made here, as the chart below illustrates; the intermediate participant group inserted longer prothetic vowel than advanced participants in general. This again provided further support for the time advantage advanced participants had over intermediate L2 learners. 
Figure 7.1.b: Duration of the prothetic vowel for non \#sC cluster groups

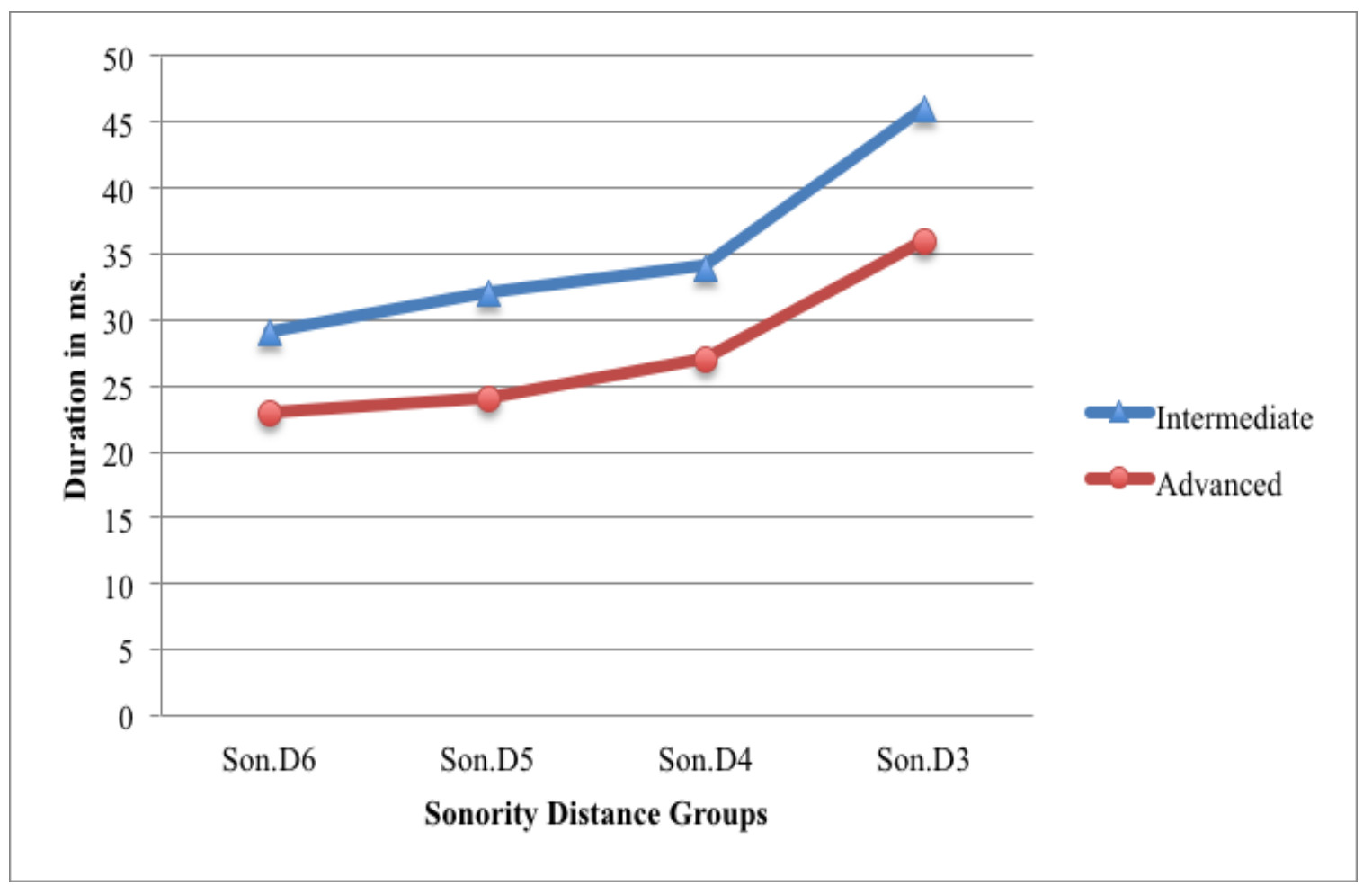

It should be noted here, however, that the durational differences of the prothetic vowel between the sonority distance groups (at least Son.D 6, Son.D 5 and Son.D 4) were rather small, which does not tell us much about the influence of markedness between these clusters. Duration of the prothetic vowel for non \#sC clusters cannot be explained by the influence of sonority. It might just be a natural result of transfer.

The results obtained for the prothetic vowel duration from both \#sC and non \#sC sonority distance groups were consistent for both of the participant groups. Results revealed two tendencies: 1) shorter prothetic vowel were inserted in less marked clusters and as markedness of the cluster group increased the duration of the prothetic vowel increased as well (this was particularly true among \#sC cluster groups) 2) intermediate participants generally tended to insert longer prothetic vowels than advanced participants. 


\subsection{Summary of the Results:}

This study was conducted to determine the pattern by which L2 learners from two proficiency levels would acquire English initial onsets. In particular, this study aimed to examine the markedness based on sonority effect on the order of the acquisition and on the processes employed on errors. In addition, it explored frequency effects to examine whether or not it had an influence on the results. Results from percentages of correct productions showed that markedness was more relevant to the \#sC clusters for both groups than it was for non \#sC clusters. While results from \#sC clusters were best explained by markedness, non \#sC clusters were best explained by L1 transfer. In this

study, the pattern observed between groups did not conform with the pattern predicted by frequency. Such finding ruled out the role of input frequency.

Since the error pattern employed by participants in this study was "prothesis", an acoustical analysis of the inserted vowel was performed. It was hypothesized that markedness of the cluster would determine the duration of the vowel; more marked clusters would have longer vowels and vice versa. Results supported this hypothesis across all $\#_{\mathrm{s} C}$ cluster groups. However, the non $\mathrm{AsC}_{\mathrm{s}}$ cluster groups did not show much variation. Such consistency in vowel duration for non $\#_{\mathrm{sC}}$ clusters suggested that L1 transfer has stronger influence on non \#sC cluster groups than markedness, because, unlike markedness, L1 transfer treats all items the same way. 


\section{CHAPTER 5. Conclusions}

\subsection{Summary of the thesis:}

The purpose of this study was to examine the production of 17 English initial double onset clusters by two Saudi Arabian participant groups in order to observe the order of acquisition and nature of errors. Two approaches (i.e., markedness and frequency of input) were explored in order to determine which approach would offer a better explanation for the observed patterns. Because of the different behaviors between \#sC clusters and non $\# \mathrm{sC}$ clusters found in the literature, the consonant clusters in question were divided into two groups $\#_{\mathrm{s}} \mathrm{C}$ clusters and non $\mathrm{AsC}_{\mathrm{S}}$ clusters. For each of these two groups of clusters, markedness predicted a hierarchy where less marked clusters were expected to be acquired before more marked ones. Despite the different degrees of markedness of the clusters, input frequency predicted a totally different hierarchy where some very marked clusters, such as the SSP violating clusters, were expected to be acquired first because of their higher frequency of occurrence in English.

Input frequency did not provide a good explanation for the observed patterns in this study. Markedness, however, generally provided a satisfactory explanation. Results from the $\mathrm{AsC}_{\mathrm{S}}$ clusters from both participant groups supported the predictions made by markedness based on sonority. This was not exactly the same with non \#sC clusters; therefore, results from non \#sC clusters were best accounted for by $\mathrm{L} 1$ transfer. The asymmetrical pattern between the $\mathrm{AsC}_{\mathrm{s}}$ and non \#sC clusters found in the results of the current study further supported the separation in analyzing the data.

Results from the duration of the prothetic vowel from $\#_{\mathrm{sC}}$ clusters were consistent with the predictions made regarding the duration based on sonority distance between $\mathrm{C} 1$ 
and $\mathrm{C} 2$ in the cluster (i.e., the greater the sonority distance, the shorter the vowel in duration and vice versa). Even though results from non \#sC clusters also showed an increase in duration in the expected direction, the very small ranges between the durations further suggested the dominant influence of the L1.

In the subsequent sections of this chapter a few words about input frequency, the OPM including markedness and L1 transfer are in order. This chapter will, then, conclude with some comments on the limitations and extension of the current study.

\subsection{General Discussion:}

\subsubsection{Input Frequency in SLA:}

Although no prediction had initially been made in this study about the possible influence of input frequency, the growing interest about its possible influence in the literature made it worthwhile to examine its influence. Given the fact that this study was not a longitudinal study, where input could have been collected into a corpus, frequency analysis required obtaining the frequency of the target clusters and words used here from external corpora in order to establish an expected developmental path. The predicted pattern by input frequency was different from what markedness has predicted. Results from this study did not support the role of input frequency but rather yielded support for markedness and L1 transfer. This, however, does not entirely rule out the possible impact of frequency on the acquisition of initial clusters, in other studies.

\subsubsection{The Ontogeny Phylogeny Model:}

\subsubsection{Markedness:}

The OPM was the theoretical framework that this study adopted. The OPM states that, in marked situations, the interlanguage system is influenced by three elements: L1 
transfer, markedness or (Universals) and L2. In the initial stages of L2 learning, the OPM claims that L1 transfer is the only factor influencing the language learning. Not until the intermediate stages of L2 learning where the influence of markedness becomes stronger. This claim was supported by results from $\mathrm{H}_{\mathrm{sC}}$ clusters in the current study. The mean percentages of correct production reflected the hierarchy predicted by markedness.

Participants produced less marked \#sC clusters more correctly than more marked ones: /s + glide $/>/ \mathrm{s}+$ lateral $/>/ \mathrm{s}+$ nasal $/>/ \mathrm{s}+$ stop/ (where " $>$ " means more correctly). This is especially valid for the intermediate group since the advanced group performed highly, but showed a similar pattern, nevertheless.

During the advanced stages of learning, the OPM claims that markedness influence should diminish. This claim was also supported by the results from the current study. For the \#sC cluster groups, the advanced participants always produced all of the sonority distance groups with more than $80 \%$ of correct production, marking a complete acquisition stage.

\subsubsection{L1 Transfer:}

Markedness could not account for the results from non $\mathrm{AsC}_{\mathrm{s}}$ cluster sonority groups, since the pattern was not consistent with the prediction. Percentages of correct production were significantly different between the two participant groups. Overall, the advanced group produced all the clusters correctly with means that were over $80 \%$, which again marks the acquisition level, with only one exception - a mean of $77 \%$ of correct production. The intermediate participants showed discrepancies in the performance, which only yielded partial support for markedness. Son.D 6 and Son.D 5 were consistent with markedness prediction; however, the Son.D 3 and Son.D 4 were doing the reverse 
and better explained by transfer. Essentially, non \#sC clusters are the least marked clusters, which makes it difficult to pinpoint the exact variable influencing their performance. However, the observation of the same pattern between both participant groups suggests that L1 transfer was stronger in intermediate stages and was less influential, yet present, in the advanced stages. According to Major (2001, 2008), L1 transfer is by far the dominant factor influencing the L2 phonological acquisition.

\subsubsection{Vowel Prothesis:}

Despite the influence of markedness on some of the clusters, the process of simplification of the clusters employed by participants was $100 \%$ prothesis. This process was a direct transfer of a phonological rule from Arabic. An important point to be made here is that the transfer of the L1 phonological rule does not contradict the discussion about markedness in the case of \#sC clusters because our discussion of the vowel is concerned with the duration. The vowel insertion rule transferred from the L1 but the duration was motivated by the degree of markedness of the clusters.

The duration of the prothetic vowel and the percentages of correct production were in accordance to the degree of markedness of the cluster, the more accurate the production was, the shorter the prothetic vowel was. Compare for example, the percentages of correct production for $/ \mathrm{s}+$ glide/ $(83 \%) \mathrm{vs} . / \mathrm{s}+\mathrm{stop} /(65 \%)$ from the intermediate participants. The duration of the prothetic vowel for $/ \mathrm{s}+$ glide/ was $(21 \mathrm{~ms}$. and for $/ \mathrm{s}+\mathrm{stop} /$ was $(50 \mathrm{~ms}$.), which corresponds to the expected hierarchy predicted by markedness. For non \#sC clusters the discussion of influence of markedness on the duration or percentage of prothesis application is irrelevant because markedness did not play stronger role in the acquisition. 
The influence of markedness on the duration of the prothetic vowel has not been addressed in the literature and this study explored it from a markedness standpoint. Two interesting observations are noteworthy; one is the tendency to insert longer prothetic vowels in clusters where sonority distance is smaller. The second interesting observation is that intermediate participants tended to insert longer prothetic vowel than advanced participants did in general. These two tendencies are particularly interesting because they can tell us more about what goes on in the L2 learner's system during its developmental stages.

\subsection{Limitations and Extensions:}

This study sought to examine the production of English initial double onset clusters by participants from Saudi Arabia. The method employed was a self-paced reading task where participants read sentences containing the target words in controlled environments. In future studies, the inclusion of other varieties of Arabic, which may have different phonotactic constraints, may yield different results. Moreover, including more environments and cluster types with different lengths is needed to fully evaluate the different possible explanations for the production patterns. Also, employing different elicitation tasks may show different results. The self-paced reading task has raised some concerns regarding the possible interference of orthography on the performance. In the future, a delayed repetition task, where participants listen to sentences and then repeat them, may also be included.

Finally, the number of participants in this study was forty-six, divided equally into two groups according to their level of proficiency. The criteria in which they were selected and assigned their groups were based on their self-report and the amount of time 
they have spent learning English. In the future, the number may be increased in both groups in order to have a higher power when performing statistical analyses. Also, the selection criteria may be administrated better to include a trained native English speaker to evaluate the participants proficiency level and employ some sort of a collective score from the native speaker evaluation, number of errors and self-report. 


\section{REFERENCES}

Abrahamsson, N. (1999). Vowel epenthesis of /sC(C)/ onsets in Spanish/Swedish interphonology: A longitudinal case study. Language Learning 49, 473-508.

Abu-Mansour, M. H. (1987). A nonlinear analysis of Arabic syllabic phonology, with special reference to Makkan. (Doctoral dissertation). Retrieved from University of Florida Digital Collections. Retrieved from: http:/ufdc.ufl.edu/UF00076694/00001/1

Adjemian, C. (1976). On the Nature of Interlanguage Systems. Language Learning, 26(2), 297-320.

Andersen, R. (1983). Transfer to somewhere. In S. M. Gass \& L. Selinker (eds.), Language transfer in language learning. (pp.177-201) Rowley, MA: Newbury House.

Anderson, J. (1987). The markedness differential hypothesis and syllable structure difficulty. In G. Ioup \& S. Weinberger (eds.), Interlanguage Phonology: The Acquisition of a Second Language Sound System, (pp. 279-291) New York: Newbury House/Harper \& Row.

Archibald, J. (2003). Learning to parse second language consonant clusters. Canadian Journal of Linguistics/Revue Canadienne de Linguistique, 48(3-4). 149-177.

Ausubel, D. P., J. D. Novak, \& H. Hanesian, (1978). Educational psychology: A cognitive view. ( $2^{\text {nd }}$ Edition). New York: Holt, Rinehart, and Winston.

Baayen, R. H., Piepenbrock, R., \& van Rijn, H. (1993). The CELEX lexical database. Philadelphia, PA: Linguistic Data Consortium, University of Pennsylvania.

Barlow, J. (2001). A preliminary typology of initial clusters in English. Clinical Linguistics \& Phonetics, 15, 9-13.

Blevins, J . (1995). The syllable in phonological theory. In J. Goldsmith (ed.), Handbook of Phonological Theory. London: Blackwell

Broselow, E. (1983). Non-obvious transfer: on predicting epenthesis errors. In L. Selinker and S. Gass (eds.) Language Transfer in Language Learning, (pp. 269-280). Rowley, MA: Newbury House.

Broselow, E. (1984). An investigation of transfer in second language phonology. International Review of Applied Linguistics. 22: 253-269. 
Broselow, E. (1992). Transfer and Universals in Second Language Epenthesis. Language Transfer in Language Learning (pp. 71-86). Amsterdam: John Benjamins

Broselow, E., \& Finer, D. (1991). Parameter setting in second language phonology and syntax. Second Language Research 7: 35-59.

Cardoso, W. (2008). The development of sC onset clusters in interlanguage: markedness vs. frequency effects. In R. Slabakova (Ed.), Proceedings of the 9th Generative Approaches to Second Language Acquisition Conference (pp. 15-29). Somerville, MA: Cascadilla Proceedings Project.

Cardoso, W., \& Liakin, D. (2009). When input frequency patterns fail to drive learning: evidence from Brazilian Portuguese English. In B. Baptista, A. Rauber, \& M. Watkins (Eds.), Recent research in second language phonetics/phonology: perception and production (pp. 174-202). Newcastle Upon Tyne: Cambridge Scholars.

Cardoso, W., John, P., \& French, L. (2009). The perception of sC onset clusters in second language phonology: a variationist perspective. In B. Baptista, A. Rauber, M. Watkins (Ed.), Recent Research in Second Language Phonetics/Phonology: A Variationist Perspective (pp. 203-233). Newcastle Upon Tyne: Cambridge Scholars.

Carlisle, R. S. (1988). The effect of markedness on epenthesis in Spanish/English interlanguage phonology. Issues and Developments in English and Applied Linguistics 3: 15-23.

Carlisle, R. S. (1991). The influence of environment on vowel epenthesis in Spanish/English interphonology. Applied Linguistics 12: 76-95.

Carlisle, R. S. (1992). Environment and markedness as interacting constraints on vowel epenthesis. In J. Leather \& A. James (Eds.), New Sounds '92 (pp. 64-75). Amsterdam: University of Amsterdam Press.

Carlisle, R. S. (1994). Markedness and environment as internal constraints on the variability of interlanguage phonology. In M. Yavaş (Ed.), First and Second Language Phonology (pp. 223-249). San Diego: Singular Publishing Company.

Carlisle, R. S. (1997). The modification of onsets in a markedness relationship: Testing the Interlanguage Structural Conformity Hypothesis. Language Learning 47: $327-361$.

Carlisle, R. S. (1998). The acquisition of onsets in a markedness relationship: A longitudinal study. Studies in Second Language Acquisition 20: 245-260. 
Carlisle, R. S. (2002). The Acquisition of Two and Three Member Onsets: Time III of a Longitudinal Study. In A. James \& J. Leather (Eds.), New Sounds 2000 (pp. 4247). Klagenfurt, Austria: University of Klagenfurt Press.

Carlisle, R. S. (2006). The sonority cycle and the acq uisition of complex onsets. In B. O. Baptista, \& M. A. Watkins (Eds.), English with a Latin beat: Studies in Portuguese/Spanish English Interphonology (pp. 105-138). Amsterdam: Johns Benjamins.

Carlisle, R.S. (1988). The effects of markedness on epenthesis in Spanish/English interlanguage phonology. Issues and Developments in English and Applied Linguistics, 3, 15-23.

Carter, M.G. (2004). Sibawayhi. London: Tauris.

Clements, G. N. (1990). The role of the sonority cycle in core syllabification. In J. Kingston \& M. Beckman (Eds.), Papers in laboratory phonology I: between the grammar and the physics of speech (pp. 283-333). Cambridge: Cambridge University Press.

Clements, G.N. \& E. Hume. (1995). The internal organization of speech sounds. In J. Goldsmith (ed.), (pp. 245-306) Handbook of Phonology. London: Blackwell.

Corder, S. P. (1971). Idiosyncratic dialects and error analysis. IRAL, 9(2), 147-160

Corder, S. P. (1981). Error Analysis and Interlanguage. Oxford: Oxford University Press

Corder, S. P. (1992). Introduction to Applied Linguistics . Mexico: Limusa

Eckman, F. (1977). Markedness and the contrastive analysis hypothesis. Language Learning, 27, 315-330.

Eckman, F. (1981). On the naturalness of interlanguage phonological rules. Language Learning, 31, 195-216

Eckman, F. (1991). The Structural Conformity Hypothesis and the acquisition of consonant clusters in the interlanguage of ESL learners. Studies in Second Language Acquisition 13. 23-41.

Eckman, F. (1991). The Structural Conformity Hypothesis and the acquisition of consonant clusters in the interlanguage of ESL learners. Studies in Second Language Acquisition, 13: 23-41. 
Eckman, F. (1996). A functional-typological approach to second language acquisition theory. In W. C. Ritchie \& T. K. Bhatia (eds.) Handbook of Second Language Acquisition, (pp. 195-211). San Diego: Academic Press

Eckman, F. (2008). Typological Markedness and Second Language Phonology. In Jette G. Hansen Edwards and Mary L. Zampini (ed.) Phonology and Second Language Acquisition. (pp. 95-116). Philadelphia: John Benjamins.

Eckman, F. and Iverson, G. (1993). Sonority and markedness among onset clusters in the interlanguage of ESL learners. Second Language Research 9 (3): 234-252.

Eckman, F. R. (1985). Some theoretical and pedagogical implications of the Markedness Differential Hypothesis. Studies in Second Language Acquisition 7: 289-307.

Eckman, F. R., \& Iverson, G. K. 1994. Pronunciation difficulties in ESL: Coda consonants in English interlanguage. In M. Yavaş (ed.) First and second language phonology (pp. 251-265) San Diego, CA: Singular.

Edwards, H. \& Zampini, J. (2008) Phonology and second language acquisition. Philadelphia, John Benjamins.

Edzard, L. (2000). Sibawayhi's observations on assimilatory processes and resyllabification in the light of optimality theory. Journal of Arabic and Islamic Studies, 3, 48-65

Ellis, R. (1994). The study of second language acquisition. Oxford: Oxford University Press.

Fries, C. (1945). Teaching and Learning English as a Second Language. Ann Arbor: University of Michigan Press

Gadoua, A. H. (2000). Consonant clusters in Quranic Arabic. Cahiers linguistiques d'Ottawa 28, 59-85.

Gafos, A. (2003). Greenberg's asymmetry in Arabic: A consequence of stems in paradigms. Language, 79(2), 317-357.

Gass, S. M., \& Selinker, L. (1983) Language transfer in language learning. Rowley, MA: Newbury House.

Gass, S. M., \& Selinker, L. (1992) Language transfer in language learning. Amsterdam: John Benjamins.

Giegerich, H. (1992). English phonology: an introduction. Cambridge, UK: Cambridge University Press. 
Gierut, J. A. (1999). Syllable onsets: clusters and adjuncts in acquisition. Journal of Speech, Language, and Hearing Research. 42, 708-726.

Goad, H. (2011). The representation of sC clusters. In M. Van Oostendorp, C. Ewen, E. Hume, \& K. Rice (Eds.), The Blackwell companion to phonology (pp. 2-40). Malden, Massachusetts: Wiley-Blackwell.

Goad, H., \& Rose, Y. (2004). Input elaboration, head faithfulness and evidence for representation in the acquisition of left-edge clusters in West Germanic. In R. Kager, J. Pater, \& W. Zonneveld (Eds.), Constraints in phonological acquisition (pp. 109-157). Cambridge: Cambridge University Press.

Greenberg, J. (1978). Language universals. The Hague: Mouton.

Greenberg, J. H. (1965). Some generalizations concerning initial and final consonant sequences. Linguistics, 18, 5-34.

Haddad, Y. (2005). Etymological itineraries in second language phonology: The case of Arabic. Rutgers Optimality Archive. Columbia University, 784-1105.

Han, Z-H. (2004). Fossilization in Adult Second Language Acquisition. Clevedon: Multilingual Matters. Studies in Second Language Acquisition, 27(4), 627-629

Han, Z-H., \& Odlin, T. (eds.). (2006). Studies of fossilization in second language acquisition. Clevedon/Buffalo/Toronto: Multilingual Matters.

Hansen-Edwards, J. (in press). The role of input frequency, universals, and L1 transfer in the acquisition of English L2 onsets by native speakers of Cantonese, Mandarin Chinese, and Vietnamese. In M. Yavaş (Ed.), Unusual Productions in Phonology: Universals and Language-Specific Effects. Psychology Press.

Hefter, H. (2012). The acquisition of /s/ + consonant onset clusters: A longitudinal study. MPhil Thesis, Concordia University, Monteral, Quebec, Canada.

Hogg, R. \& McCully, C. (1987). Metrical Phonology: A Coursebook. Cambridge: Cambridge University Press.

Kaye, A. S. (2009). Arabic. In: Bernard Comrie (ed.). The world's major languages. (pp. 560-577) Routledge, London

Keating, P. (1983) Comments on the jaw and syllable structure. Journal of Phonetics, $11,401-406$. 
Kellerman, E. \& Sharwood Smith, M. (1986). Crosslinguistic influence in SLA: an introduction. In M. Sharwood Smith E. Kellerman (Eds.), Crosslinguistic Influence in Second Language Acquisition, (pp. 1 - 10). Oxford: Pergamon Press

Kenstowicz, Michael. (1994). Phonology in Generative Grammar. Blackwell Publishers.

Kucera, H., \& Francis, W. N. (1967). Computational analysis of present day American English. Providence: Brown University Press.

Ladefoged, P. (2001) A Course in Phonetics. New York; Harcourt College.

Lado, R . (1957). Linguistics Across Cultures. Applied Linguistics for Language Teachers. Ann Arbor. University of Michigan Press

Lado, R. (1964). Language teaching, a scientific approach. New York: Mcgraw- Hill, Inc.

Lindblom, B. (1983). Economy of speech gestures. In P. F. MacNeilage (ed), The Production of Speech (pp. 217-245). New York: Springer-Verlag.

Major, R. C. (1987). A model for interlanguage phonology. In G. Ioup \& S. Weinberger (ed.) Interlanguage Phonology: The Acquisition of a Second Language Sound System (pp. 101-125). New York: Newbury House

Major, R. C. (2001). Foreign accent: the ontogeny and phylogeny of second language phonology. Mahwah, NJ: Lawrence Erlbaum.

Major, R. C. (2008). Transfer in second language phonology. In J. G. Hansen Edwards \& M. L. Zampini (eds.), (pp. 63-94) Phonology and second language acquisition, Philadelphia: John Benjamins.

McCarthy, J. (2005). Optimal paradigms. In Downing, L., T. Alan Hall \& R. Raffelsiefen (eds.), Paradigms in phonological theory. (pp. 170-210) Oxford: Oxford University Press.

Morelli, F. (2003). The relative harmony of /s+Stop/ on sets: Obstruent clusters and the sonority sequencing principle. In C. Fery, \& R. van de Vijver (eds.), The syllable in optimality theory (pp. 356-37). New York: Cambridge University Press.

Odlin, T. (1989). Language transfer. Cambridge, UK: Cambridge University Press.

Odlin, T. (2003). Cross-linguistic influence. In C. J. Doughty and M. H. Long (ed) Handbook of Second Language Acquisition, (pp. 436-486). Malden, MA: Blackwell 
Ohala, D. K. (1999). The influence of sonority on children's cluster reductions. Journal of Communication Disorders, 32, 397-422.

Oller, J. W., \& Ziahosseiny, S. M. (1970). The contrastive analysis hypothesis and spelling errors. Language Learning 20: 183-189.

Prince, P. J. (1980). Sonority and syllabicity: Acoustic correlates of perception. Phonetica, 37, 327-343.

Rauber, A. S. (2006). Production of English initial /s/ clusters by speakers of Brazilian Portuguese and Argentine Spanish. In B. Baptista \& M. Watkins (Ed.), English with a Latin Beat- studies in Portuguese/Spanish English Interlanguage, (pp. 155167), Amsterdam: John Benjamins.

Roach, P. 2000. English Phonetics and Phonology, A Practical Course. ( ${ }^{\text {rd }}$ Edition). Cambridge: Cambridge University Press.

Selinker, L. (1972). Interlanguage. International Review of Applied Linguistics, 10(3), 209-231

Selkirk, E. (1984). On the major class features and syllable theory. In M. Aranoff, \& R. T. Oehrle (Eds.), Language sound structure: studies in phonology presented to Morris Halle by his teacher and students. (107-136). Cambridge, MA: The MIT Press.

Tarone, E. (1980). Communication strategies, foreigner talk, and repair in interlanguage studies. Language Learning, 30, 417-431

Tarone, E. (1988). Variation in Interlanguage. London: Edward Arnold.

Wardhaugh, R. (1970). The contrastive analysis hypothesis. TESOL Quarterly 4(2) 123130.

Weinreich, U. (1953). Languages in Contact. The Hague: Mouton

Yavaş, M., \& Barlow J. (2006). Acquisition of \#s C clusters in Spanish-English bilingual children. Journal of Multilingual Communication Disorders 4(3), 182-193.

Yavaş, M. (2011). Applied English Phonology (2 ${ }^{\text {nd }}$ Edition) Wiley-Blackwell

Yavaş, M. (2003). Role of sonority in developing phonologies. Journal of Multilingual Communication Disorders, 1(2), 79-98.

Yavaş, M. (2010). Sonority and the acquisition of /s/ clusters in children with phonological disorders. Clinical Linguistics and Phonetics. 24:3, 169-176 
Yavaş, M. (2013). What explains the reductions in /s/ cluster s: sonority or [continuant]?. Clinical Linguistics and Phonetics, 27(6-7), 394-403

Yavaş, M. \& Barlow, J. (2006). Acquisition of \#sC clusters in Spanish -English bilingual children. Journal of Multilingual Communication Disorders 4(3), 182193.

Yavaş, M. \& McLeod, S. (2010). Acquisition of /s/ clusters in English-speaking children with phonological disorders. Clinical Linguistics and Phonetics 24(3), 177- 187.

Yavaş, M. (2010). Acquisition of /s/ clusters in Spanish - English bilingual children with phonological disorders. Clinical Linguistics and Phonetics 24(3), 188-198.

Yavaş, M. \& Someillan, M. (2005), Patterns of Acquisition of / s /-clusters in SpanishEnglish Bilinguals. Journal of Multilingual Communication Disorders. 3(1), 5055.

Yavaş, M. , Ben-David, A, Gerrits, E., Kristoffersen, K. \& Simonsen, H. (2008). Sonority and cross - linguistic acquisition of initial s - clusters. Clinical Linguistics and Phonetics 22(6), 421 - 441

Yildiz, Y. (2005). The structure of initial/s/-clusters: evidence from L1 and L2 acquisition. In M. Tzakosta, C. Levelt, \& J. van der Weijer (Eds.) Developmental Paths in Phonological Acquisition. Special issue, Leiden Working Papers in Linguistics, 2(1), 163-187.

Zamuner ,T, Gerken L. A., \& Hammond M. (2005). The acquisition of phonology based on input: A closer look at the relation of cross-linguistic and child language data. Lingua. 115(10): 1329-1474

Zec, D. (1995). Sonority constraints on syllable structure. Phonology, 12(1), 85-129. 
APPENDICES

APPENDIX A

Language History Questionnaire

\section{Contact Information:}

Name: Email:

Telephone: Today's

Date:

\section{Questions:}

1. Age:

2. Sex:

3. Education (highest degree obtained or school level attended):

4. Country of origin:

5. Country of residence:

6. If questions 4 and 5 are the same, how long have you lived in a foreign country where your second language is spoken? If they are different, how long have you been in the country of your current residence?

7. What is your first language?

8. Do you speak a second language? If so, what is your second language?

(If you do not speak a second language, you do not need to proceed and have finished the form)

9. At what age did you start to learn your second language ...

- At home?

- In school?

- After arriving in the second language speaking country?

10. How did you learn your second language up to this point? (check all that apply)

- Mainly through formal classroom instruction

- Mainly through interacting with people 
- A mixture of both

- Other (please specify)

11. List all foreign language you know in order of most proficient to least proficient. Rate

\begin{tabular}{|l|l|l|l|l|}
\hline Language & $\begin{array}{l}\text { Reading } \\
\text { proficiency }\end{array}$ & $\begin{array}{l}\text { Writing } \\
\text { proficiency }\end{array}$ & $\begin{array}{l}\text { Speaking } \\
\text { fluency }\end{array}$ & $\begin{array}{l}\text { Listening } \\
\text { ability }\end{array}$ \\
\hline & & & & \\
\hline & & & & \\
\hline
\end{tabular}

your ability in the following aspects using the scale (write down numbers in the table):

1-very poor 2-poor 3-fair 4-functional 5-good 6-very good 7-native-like 12. Provide the age at which you were first exposed to each foreign language in terms of speaking, reading, and writing and the number of years you have spent on learning each language:

\begin{tabular}{|l|l|l|l|l|}
\hline Language & $\begin{array}{l}\text { Age exposed to } \\
\text { speaking }\end{array}$ & $\begin{array}{l}\text { Age exposed to } \\
\text { reading }\end{array}$ & $\begin{array}{l}\text { Age exposed to } \\
\text { writing }\end{array}$ & $\begin{array}{l}\text { Number of } \\
\text { years learning }\end{array}$ \\
\hline & & & & \\
\hline
\end{tabular}

13. Do you have a foreign accent in the languages you speak? If so, please rate the strength of your accent on a scale from 1 to 7 (see above):

\begin{tabular}{|l|l|l|}
\hline Language & Accent (circle one) & Strength of accent \\
\hline & & \\
\hline
\end{tabular}

14. What language do you usually speak to your mother at home? (If not applicable for any reason, write $\mathrm{N} / \mathrm{A}$ )

15. What language do you usually speak to your father at home? (If not applicable for any reason, write $\mathrm{N} / \mathrm{A}$ )

16. What languages can your parents speak fluently? (If not applicable for any reason, write N/A)

- Mother:

- Father:

17. What language or languages do your parents usually speak to each other at home? (If not applicable for any reason, write N/A) 
18. Write down the name of the language in which you received instruction in school, for each schooling level:

- Primary/Elementary School

- Secondary/Middle School

- High School

- College/University

19. Estimate, in terms of percentages, how often you use your native language and other languages per day (in all daily activities combined. Total should equal 100\%):

- Native language __ $\%$

- Second language ___ $\%$

- Other languages ___ $\%$ (Specify ___

20. Estimate, in terms of hours per day, how often you watch TV or listen to radio in your native language and other languages per day.

- Native language:

- Second language:

- Other languages (specify):

21. Estimate, in terms of hours per day, how often you read newspapers, magazines, and other general reading materials in your native language and other languages per day.

- Native language:

- Second language:

- Other languages (specify):

22. Estimate, in terms of hours per day, how often you use your native language and other languages per day for work or study related activities (e.g., going to classes, writing papers, talking to colleagues, classmates, or peers).

- Native language:

- Second language:

- Other language:

23. In which languages do you usually:

- Add, multiply, and do simple arithmetic?

- Dream? 
- Express anger or affection?

24. When you are speaking, do you ever mix words or sentences from the two or more languages you know? (If no, skip to question 26)

25 . List the languages that you mix and rate the frequency of mixing in normal conversation with the following people, on a scale from 1 (mixing is very rare) to 5 (mixing is very frequent). Write down the number in the box.

\begin{tabular}{|l|l|l|}
\hline Relationship & Languages mixed & Frequency of mixing \\
\hline Spouse/family members & & \\
\hline Friends & & \\
\hline Co-workers & & \\
\hline
\end{tabular}

26. In which language (among your best two languages) do you feel you usually do better? Write the name of the language under each condition.

\begin{tabular}{|l|l|l|}
\hline Activity & At Home & At work \\
\hline Reading & & \\
\hline Writing & & \\
\hline Speaking & & \\
\hline Understanding & & \\
\hline
\end{tabular}

27. If you have lived or travelled in other countries for more than three months, please indicate the name(s) of the country or countries, your length of stay, and the language(s) you leaned or tried to learn.

28. If you have taken a standardized test of proficiency for languages other than you native language (e.g., TOEFL or Test of English as a Foreign Language), please indicate the scores you received for each.

\begin{tabular}{|l|l|l|}
\hline Language & Scores & Name of the Test \\
\hline & & \\
\hline
\end{tabular}

29. If there is anything else that you feel is interesting or important about your language background or language use, please comment below: 


\section{APPENDIX B}

Non \#sC clusters

\begin{tabular}{|c|c|c|c|}
\hline & $\begin{array}{l}\mathrm{V} \\
\mathrm{O}\end{array}$ & 1 & $\mathrm{r}$ \\
\hline $\mathrm{p}$ & $\begin{array}{l}/ \mathrm{i} / \\
/ \mathfrak{\gtrless} / \\
/ \mathrm{u} /\end{array}$ & $\begin{array}{l}\text { She said please to him } \\
\text { Jill made a good plan for us } \\
\text { Mars and Pluto are planets }\end{array}$ & $\begin{array}{c}\text { Erick met that priest on Monday } \\
\text { I watched prank programs } \\
\text { yesterday } \\
\text { He had proof to convince me }\end{array}$ \\
\hline $\mathrm{b}$ & 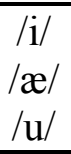 & $\begin{array}{l}\text { The dog didn't bleed to death } \\
\text { She likes red and black shirts } \\
\text { Emma doesn't want blue hair }\end{array}$ & $\begin{array}{l}\text { That breeze was very refreshing } \\
\text { I prefer that brand of bikes } \\
\text { He had bruises on his hand }\end{array}$ \\
\hline $\mathrm{k}$ & $\begin{array}{l}\mathrm{i} / \\
/ \mathfrak{\gtrless} / \\
/ \mathrm{u} /\end{array}$ & $\begin{array}{l}\text { Bill will not clean the lab } \\
\text { Last class was interesting } \\
\text { I had clues for the puzzles }\end{array}$ & $\begin{array}{l}\text { I put cream on my coffee } \\
\text { I saw a bad crash last night } \\
\text { The flight crew came late }\end{array}$ \\
\hline $\mathrm{g}$ & 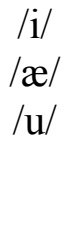 & $\begin{array}{l}\text { He went to Harvard Glee Club } \\
\text { The red glasses fit me better } \\
\text { I used glue for the table }\end{array}$ & $\begin{array}{l}\text { He never used green markers } \\
\text { I put grass in the vase } \\
\text { We should group the books } \\
\text { together }\end{array}$ \\
\hline $\mathrm{f}$ & $\begin{array}{l}/ \mathrm{i} / \\
/ \mathfrak{\gtrless} / \\
/ \mathrm{u} /\end{array}$ & $\begin{array}{l}\text { Nick did not flee to London } \\
\text { We brought eight flags today } \\
\text { They had flu shots this year }\end{array}$ & $\begin{array}{l}\text { The Wi-Fi is not free here } \\
\text { Kim visited France last year } \\
\text { I bought fruit for you }\end{array}$ \\
\hline
\end{tabular}


\#sC Clusters

\begin{tabular}{|c|c|c|c|c|c|c|c|}
\hline & $\mathrm{p}$ & $\mathrm{t}$ & $\mathrm{k}$ & $\mathrm{m}$ & $\mathrm{n}$ & 1 & W \\
\hline$S$ & $\begin{array}{l}\text { He did } \\
\text { not speak } \\
\text { with me } \\
\text { I don't } \\
\text { read } \\
\text { spam } \\
\text { emails }\end{array}$ & $\begin{array}{l}\text { They } \\
\text { didn't } \\
\text { steal my } \\
\text { money } \\
\text { Sam } \\
\text { used the } \\
\text { red } \\
\text { stamp } \\
\text { today } \\
\\
\text { I got a } \\
\text { three- } \\
\text { legged } \\
\text { stool } \\
\text { today }\end{array}$ & $\begin{array}{l}\text { I went } \\
\text { skiing } \\
\text { last } \\
\text { winter } \\
\text { You } \\
\text { should } \\
\text { scan } \\
\text { your } \\
\text { passport } \\
\\
\text { I love } \\
\text { my old } \\
\text { school a } \\
\text { lot }\end{array}$ & $\begin{array}{l}\text { The } \\
\text { blood } \\
\text { smear } \\
\text { revealed } \\
\text { malaria } \\
\text { She } \\
\text { would } \\
\text { smash } \\
\text { the } \\
\text { window } \\
\text { I had a } \\
\text { fast and } \\
\text { smooth } \\
\text { trip }\end{array}$ & $\begin{array}{l}\text { The kid } \\
\text { sneezed } \\
\text { a lot } \\
\text { today } \\
\text { I will } \\
\text { not snap } \\
\text { at her } \\
\text { I don't } \\
\text { snoop } \\
\text { on my } \\
\text { friends }\end{array}$ & 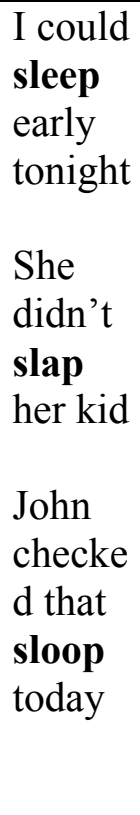 & $\begin{array}{l}\text { Ahmed } \\
\text { sweeps } \\
\text { his } \\
\text { room at } \\
\text { night } \\
\text { Ronald } \\
\text { swam } \\
\text { across } \\
\text { the } \\
\text { pool } \\
\text { She } \\
\text { would } \\
\text { swoon } \\
\text { over } \\
\text { him }\end{array}$ \\
\hline
\end{tabular}

